\title{
ENFORM: An ENergy InFORMation System
}

\author{
C. M. Heeb \\ W. L. Purcell \\ B. M. Cole
}

March 1977

Prepared for the Energy Research and Development Administration under Contract EY-76-C-06-1830

\section{\%ัต Battelle}


NOTICE

This report was prepared as an account of work sponsored by the United States Government. Neither the United States nor the Energy Research and Development Administration, nor any of their employees, nor any of their contractors, subcontractors, or their employees, makes any warranty, express or implied, or assumes any legal liability or responsibility for the accuracy. completeness or usefuiness of any information, apparatus, product or process disclosed, or represents that its use wouid not intringe privately owned rights.

\author{
PACIFIC NORTHWEST LABORATORY \\ operated by \\ BATTELLE \\ for the \\ ENERGY RESEARCH AND DEVELOPMENT ADMINISTRATION \\ Under Contract EY-76-C-06-1830
}

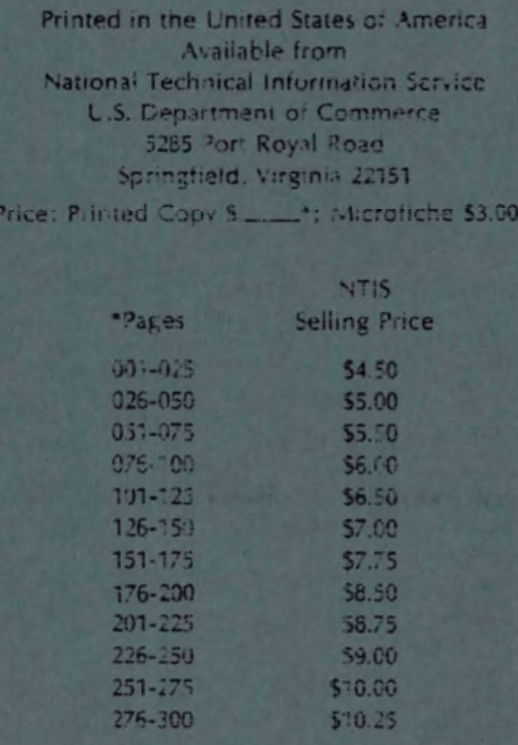


An ENergy InFORMation System

by

C.M. Heeb

W.L. Purcell

B.M. Cole

January 1977

\section{BATTELLE}

Pacific Northwest Laboratories

Richland, Washington 99352 


\section{PREFACE}

The operation of nuclear fuel cycle facilities will introduce noxious materials, both radiological and chemical, into the environment through routine discharges of both liquid and airborne effluents. The environmental implications of continued development of existing nuclear fuel cycles and implementation of new fuel cycles must be determined systematically to assure the timely development and demonstration of technologies which control or el iminate the discharge of these materials.

To address this need for a comprehensive systems analysis of effluent control technologies for the nuclear fuel cycles, ERDA's Division of Environmental Control Technology has initiated a program, Analysis of Nuclear Fuel Cycles, at Battelle, Pacific Northwest Laboratories (PNL). The objective of this program is to identify areas in developing nuclear fuel cycles (1) where environmental controls seem to be inadequate, (2) where inconsistencies and conflicts exist in environmental policy, and (3) where improved environmental controls can be justified on a cost/benefit basis (i.e., ensure that funds are not expended in cases where neither potential effects nor public concerns warrant such expenditures). The program initially focuses on current and "near future" LWR technology. Later work will focus on cost/benefit analyses of advanced LWR alternatives and alternative control technologies for LMFBR fuel cycles. Further work will concentrate on analyzing other advanced nuclear energy systems (e.g., fusion) and integrating results from the various energy technology studies to evaluate the environmental control technology of the nuclear industry.

This report is one of approximately ten that will be published during the course of the program. The first three reports to be published describe the analytical tools used in the study. Since these analytical methodologies have applications far beyond the scope of this study, they deserve special attention, particularly by those engaged in environmental analyses and cost/benefit studies of environmental impacts. These documents are: 

ENFORM: An ENergy InFORMation System, BNWL-2195, by C. M. Heeb, W. L. Purcell, and B. M. Cole.

Procedures for Estimating Nuclear Fuel Cycle Costs, BNWL-2210, by John Young.

Environmental Assessment Methodology for the Nuclear Fuel Cycle, BNWL-2219, by D. L. Brenchley.

The remaining reports will describe the nuclear fuel cycle facilities to be studied and the results of our analyses.

These reports are all available from the National Technical Information Service.

T. J. Kabele

Project Manager 



\section{SUMMARY}

The ENFORM system of computer codes can be used to calculate the amount of fuel material in the nuclear fuel cycle as a function of time. The material amounts are determined by an input schedule of installed electric energy generation capacity. In addition to the amount of uranium and plutonium in the fuel cycle, the system also accounts for 175 radionuclides.

The effect of the fuel cycle on the environment can be calculated for the release of radionuclides and chemicals. The released radionuclides are modeled through the use of release factors and dose coefficients applied to the contained isotopic inventories. The chemical effluents released to the environment are modeled by using simple release factors. All release factors and dose coefficients are specific for each type of plant in the nuclear fuel cycle.

The material logistics and effluent accounting features of the ENFORM system are supplemented by a fuel cycle economics package. This module provides fuel cycle processing costs and the levelized cost of power.

The ENFORM system also provides means of estimating the effect of changing nuclear growth scenarios and changing environmental control technologies on nuclear fuel cycle effluents, economics and logistics. 


\section{CONTENTS}

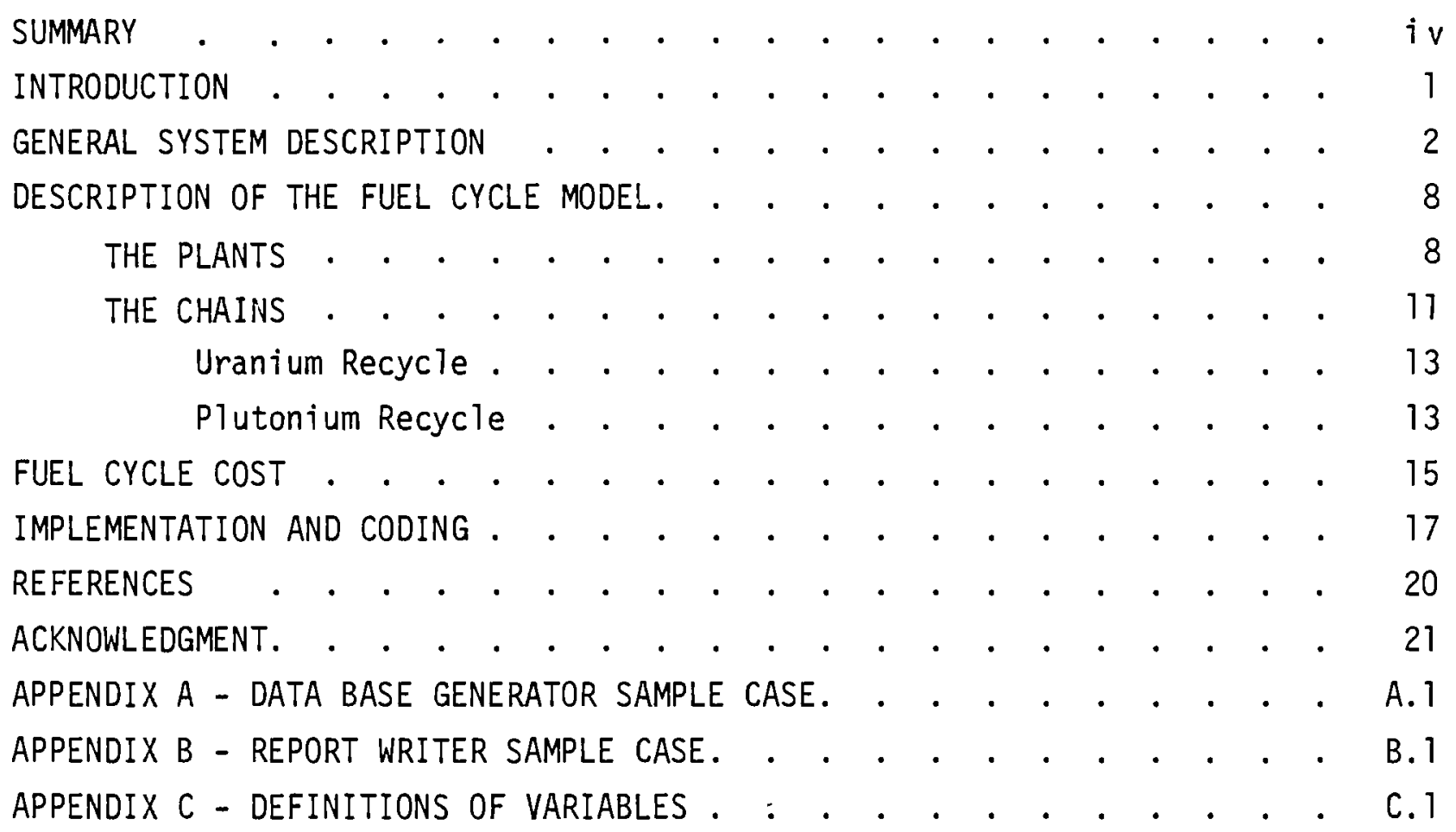





\section{INTRODUCTION}

ENFORM is a computer-based information system addressing the economics and material logistics of large-scale electric energy generation. The most important system inputs consist of electric energy generation requirements, details of plant construction scheduling, unit costs, and environmental release factors. From these inputs the ENFORM system computes the mass balances and generates the environmental releases of noxious chemicals and radionuclides from each type of plant in the fuel cycle. Fuel cycle costs and electric power costs are also computed so that cost-benefits can be assessed for various electric generation schedules (scenarios).

Much of the descriptive material contained here is of a general nature, dealing primarily with the design of the ENFORM system, while other sections of the report describe in detail the present version of the system, i.e., ENFORM-I, which is restricted to the modeling of LWRs. The designations ENFORM and ENFORM-I are used to distinguish between the general and the specific current properties of the computer codes.

This document describes not only the general system design but also ENFORM-I capabilities. It is not a user's manual and thus does not provide detailed programming information. Future versions of ENFORM will be extended to describe the economics and material logistics of LMFBRs (ENFORM-II), the LWR thorium fuel cycle, and perhaps fossil energy generation, all of which can be incorporated comfortably within the overall system design. 


\section{GENERAL SYSTEM DESCRIPTION}

A general schematic of the ENFORM system is shown in Figure 1. The input scenario, which is a table of installed nuclear generation capacity and capacity factor (that is, fraction of calendar time the plant is operating at stated capacity), is provided by year for PWRs and BWRs in the ENFORM-I version. The arithmetic product of installed capacity and capacity factor determines the energy generated in that year for that reactor type.

The Data Base Generator "solves" the fuel cycle logistics problem based on the input scenario. "Solves" means that the amount of uranium and plutonium required to generate the electric power specified by the scenario is determined, and that the point in time that the material is required is calculated for all of the steps in the fuel cycle from the uranium mine through the reprocessing plant. Both uranium and plutonium recycle are available as options. A report is written which summarizes the material flows and provides fuel cycle cost information. In addition, a massive data base is generated which contains not only the distribution in time of bulk uranium and plutonium in the fuel cycle but also the distribution of nearly 180 important radionuclides. A sample case is displayed in Appendix A.

After the data base has been generated in Pass I (Figure 1), the Report Writer module is instructed by additional input in Pass II to interrogate the data base and produce a report on any part of the data base specified, or on the entire data base. For radionuclide emissions, releases in units of radioactivity or dose can be specified. Chemical releases are specified in mass units per year per facility.

Chemical releases and radionuclide doses are not stored in the data base but are generated as needed. The data base contains the amounts of material processed in a given time period. The Report Writer module contains chemical release factors which give the amount of a given chemical release per amount of fuel material processed by the plant, i.e., kilograms of uranium. The amount of the release is merely the product of the fuel material (from the data base) and the release factor. 


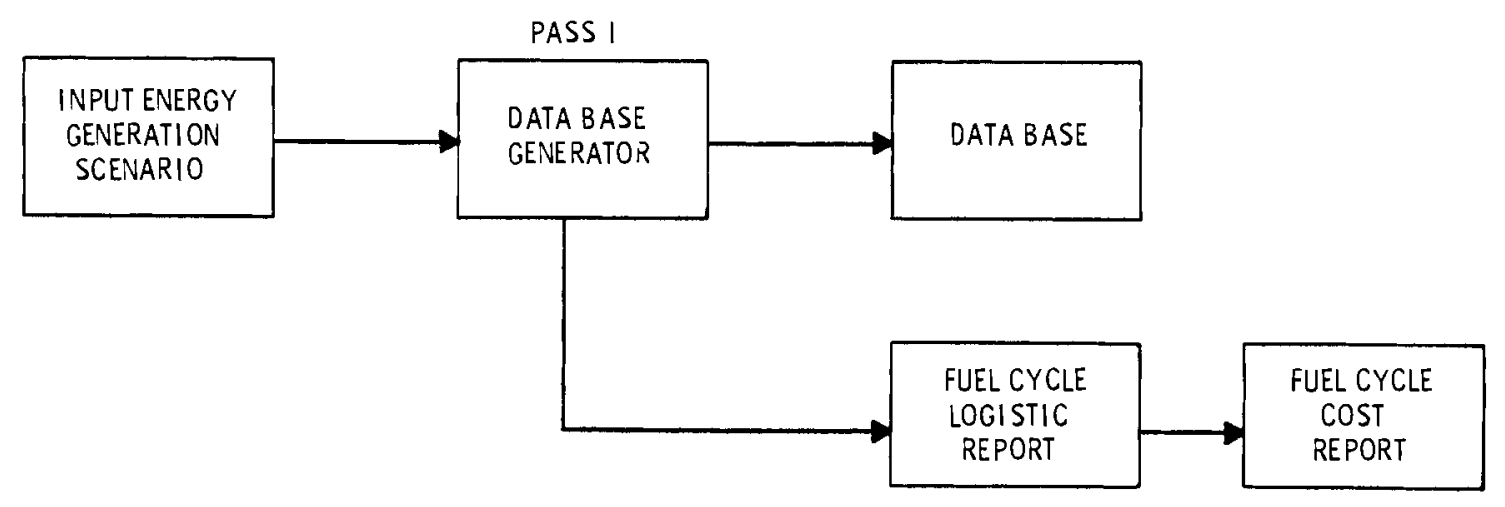

PASS 11

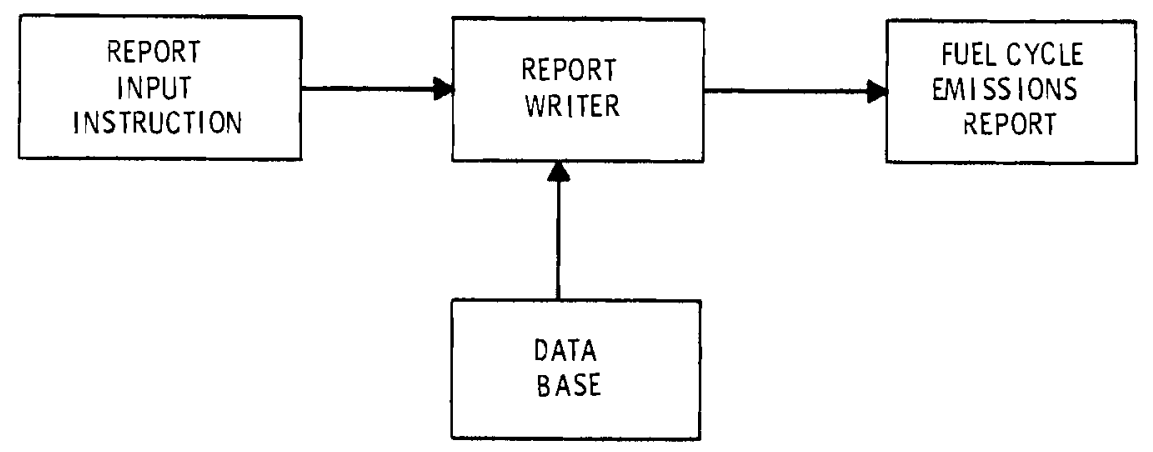

FIGURE 1. ENFORM General System Design

Dose from released radionuclides is similarly calculated except that both a dose coefficient (dose per curie released) and a release factor in terms of curies released per curie processed is required. The source term which is the amount of each radionuclide processed is contained explicitly in the data base. This is different from the chemical release calculation which is based merely on the gross amount of plant product processed. The technique of "calculate on demand" saves much information storage space and may be less expensive than retrieval from a complete, but more unwieldy, data base.

Pass I and Pass II must be repeated for each scenario. Eventually a set of data bases can be accumulated which will accommodate repeated interrogation. Technical changes in fuel cycle material release factors and shifts in interest to other radionuclides or chemical effluents not previously requested may make several interrogations necessary. 
The organization of the data base is conveniently visualized in terms of a "library" of three dimensional "volumes." The three dimensions of every volume are:

1. Time (ENFORM-I uses years)

2. Process plant module (mine, mill, conversion, etc.)

3. Material chain

The first two dimensions are self-explanatory, but some explanation for the material chain dimension is in order. A material chain is defined as a pathway through the fuel cycle for each type of material required by the reactor at any stage in its life. A chain is thus characterized by reactor type (i.e., PWR), by initial enrichment, and by final discharge exposure. A PWR, which normally replaces one-third of the core at each refueling, would have three chains for the first core, perhaps one unique first reload enrichment, and an equilibrium reload enrichment which would remain constant for all subsequent reloads. Thus, five chains would be necessary to represent the range of fuel material required for a PWR.

The advantage of describing the flow of fuel material through the fuel cycle in terms of these "chains" is that burnup and decay can be calculated "in advance" for each chain and the results can be stored away as a set of time-dependent coefficients. The coefficients are in units of isotopic mass per weight of fuel loaded into the core at the beginning of the irradiation cycle. When a particular input scenario is being calculated, it is only necessary to know the amount of fuel material charged in that particular "chain." In order to calculate the isotopic content exactly for each time period, the isotopic coefficient is multiplied by the mass of material charged.

A "volume" in the data base library contains the total amount of fuel material or the total amount of a given isotope. These amounts are distributed over chain, process step, and time (years) within each volume. The structure of the data base library is illustrated in Figure 2. 


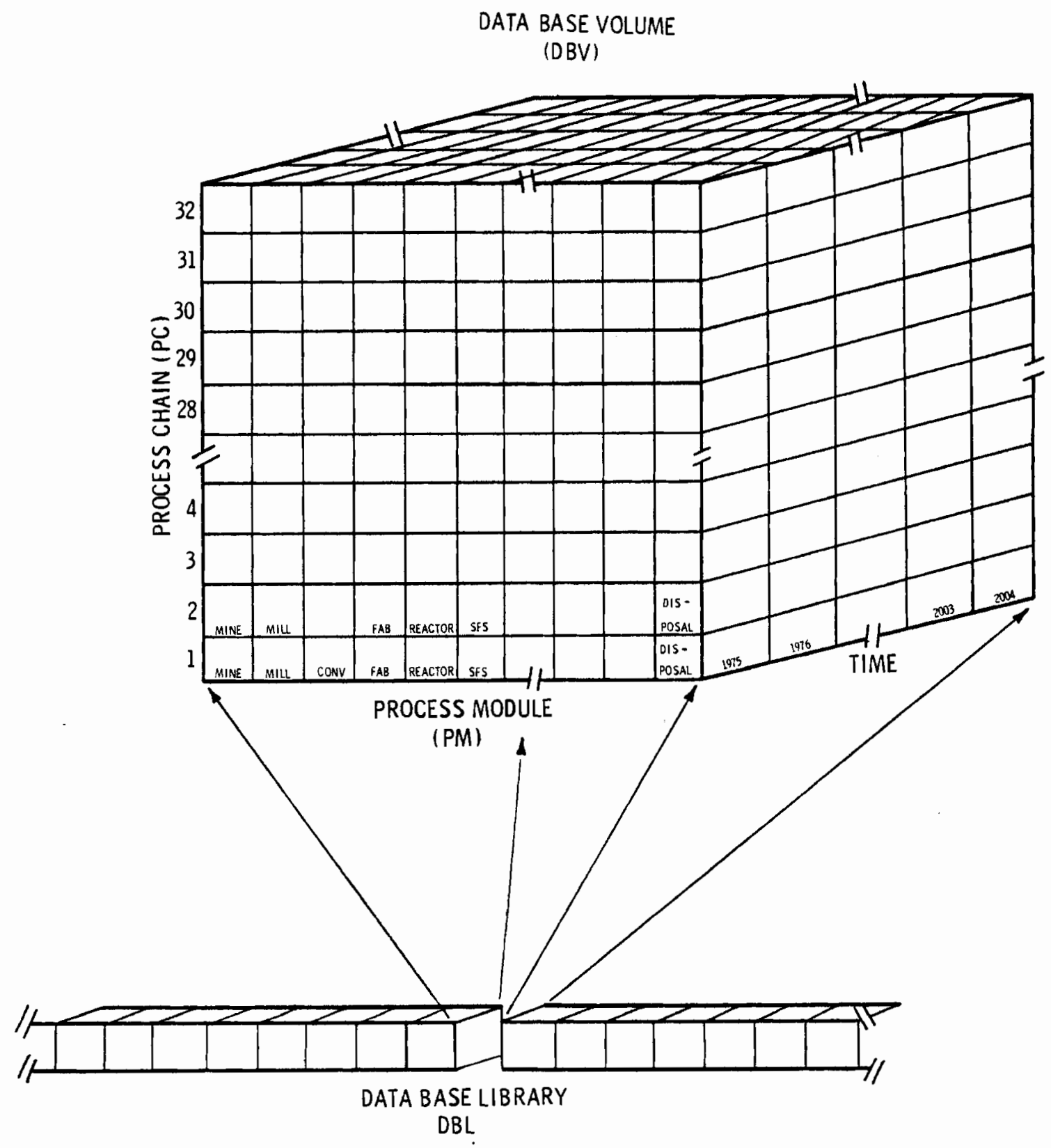

FIGURE 2. Data Base Structure 
The first task to be accomplished by the Data Base Generator is to allocate fuel material to the various chains according to the input scenario. This is first done without considering uranium or plutonium recycle, thereby establishing a maximum pool of material available for recycle. Then a second pass through time is made which modifies the previous amounts by whatever recycle option is specified in the input. The material flow for a nonrecycle and recycle chain set is illustrated in Figure 3 .

When the first Data Base Volume (DBV) containing the weight of uranium and plutonium is written, the Data Base Generator (DBG) prints the isotopic volumes by using the contents of the first volume and the isotopic coefficient files. The isotopic files were generated with the ORIGEN ${ }^{(1)}$ computer code.

The DBG and the Report Writer (RPW) modules both make use of files that are the result of external computations such as transmutation, dose rate, release factors, fixed isotopic compositions, etc. This type of file is referred to as a Template File (TPF) to distinguish it from the data base proper. The Template Files are valid for all scenarios, while the data base is strictly scenario-dependent. The final task of the DBG is to produce a report which summarizes the mass flows and pertinent fuel cycle cost information.

After the data base has been completed for a given scenario, the Report Writer (RPW) module receives from the user specific instructions which define those portions of the data base to be interrogated and the form to be used in printing the results of the interrogation. A sample case for the Report Writer is given in Appendix $B$. The computational procedure is a straightforward multiplication of the amount of material by the release factor, followed perhaps by further multiplications of unit conversion factors. The release factors and conversion factors are stored on template files which are accessed by the RPW during execution. 


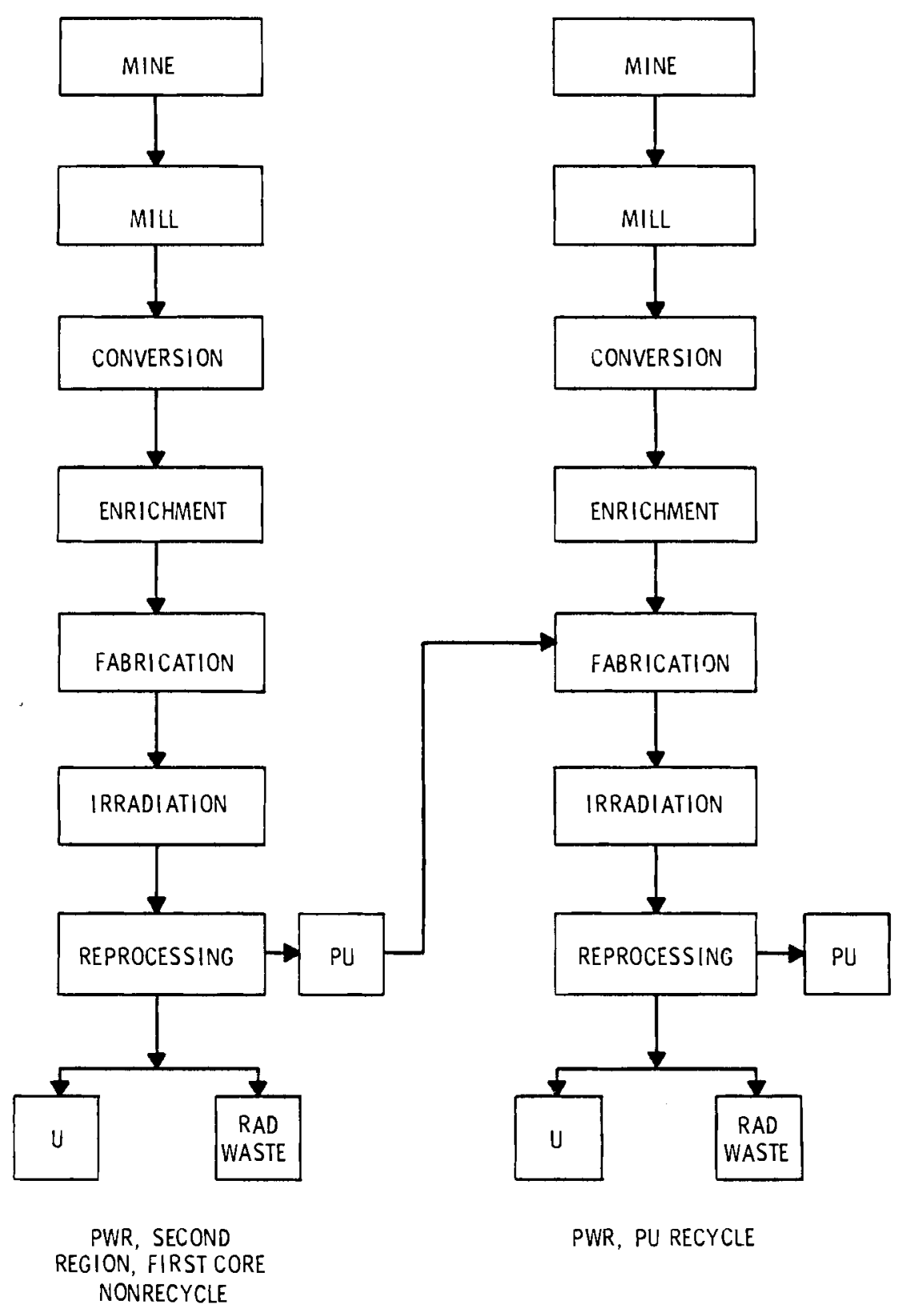

FIGURE 3. Two Sample Processing Chains 


\section{DESCRIPTION OF THE FUEL CYCLE MODEL}

This section describes the major components of the ENFORM-I model, i.e., the plants and the chains.

\section{THE PLANTS}

Table 1 lists the various plants of the fuel cycle contained in the ENFORM-I model. The residence time of a given material in any of these plant types can be specified in units of quarter years.

There are two types of uranium mines contained in the model. The ore grade may be specified by year for each of the two mine types, and the amount produced from each mine type (i.e., production split) can be specified by input. The split in output production between the two mill types can also be specified by input.

\section{TABLE 1. ENFORM-I Model Plants}

\begin{tabular}{cl}
$\begin{array}{c}\text { Plant } \\
\text { Index }\end{array}$ & \multicolumn{1}{c}{ Plant Name } \\
\cline { 1 - 2 } 2 & Open Pit Uranium Mine \\
3 & $\begin{array}{l}\text { Uranium Mill Employing the Acid Leach } \\
\text { Process }\end{array}$ \\
4 & Uranium Mi11 Employing the Alkaline \\
5 & Leach Process \\
6 & Uranium Enrichment, Gaseous Diffusion \\
7 & Fuel Fabrication, Uranium Oxide \\
8 & Fuel Fabrication, Plutonium-Uranium Oxide \\
9 & Pressurized Water Reactor (PWR) \\
10 & Boiling Water Reactor (BWR) \\
11 & Reactor Spent Fuel Storage \\
12 & Interim Spent Fuel Storage \\
13 & Reprocessing
\end{tabular}


There are also two types of fabrication plants $\left(\mathrm{UO}_{2}\right.$ plant and mixed oxide plant); their production split cannot be specified because the code does it automatically based on the plutonium recycle specified by the scenario.

The amount of fuel processed in the PWR and the BWR is determined completely by the input energy generation scenario. A11 of the power is generated in one or the other of the two generic LWR types. The key properties of the generic reactors are contained in Tables 2 and 3 . The design capacity factor (Item 6 from Tables 2 and 3 ) is used to determine the residence time of the fuel in the reactor. An annual refueling is assumed when the input capacity factor matches the design capacity factor. When the input capacity factor is less, residence time is increased proportionately, and decreased when it is more than the design value.

\section{TABLE 2. The Reference PWR}

\begin{tabular}{|c|c|c|c|}
\hline No. & Datum & Value & Unit \\
\hline 1 & Core Thermal Power & 3411 & $M w_{t}$ \\
\hline 2 & Net Electric Power & 1156 & $\mathrm{Mw}_{e}$ \\
\hline 3 & Assembly Weight (U) & 461.5 & $\mathrm{~kg}$ \\
\hline 4 & Core Fuel Weight (U) & 89.1 & MTM \\
\hline 5 & Thermal Efficiency & 0.3389 & -- \\
\hline 6 & Design Capacity Factor & 0.7867 & -- \\
\hline 7 & Assembly Rod Array & $17 \times 17$ & -- \\
\hline 8 & Rod Pitch & 1.2598 & $\mathrm{~cm}$ \\
\hline 9 & Pellet Density & 95 & $\%$ Theo. \\
\hline 10 & Pellet Diameter & 0.8192 & $\mathrm{~cm}$ \\
\hline 11 & Fuel Rod Outer Diameter & 0.9500 & $\mathrm{~cm}$ \\
\hline 12 & Clad Thickness & 0.05715 & $\mathrm{~cm}$ \\
\hline 13 & Reload Batch Size & 0.3333 & Core $\mathrm{Fr}$ \\
\hline
\end{tabular}


TABLE 3. The Reference BWR

\begin{tabular}{|c|c|c|c|}
\hline No. & Datum & Value & Unit \\
\hline 1 & Core Thermal Power & 3800 & $\mathrm{MW}_{\mathrm{t}}$ \\
\hline 2 & Net Electric Power & 1277.0 & $\mathrm{MW}_{e}$ \\
\hline 3 & Assembly Weight (U) & 188.6 & $\mathrm{~kg}$ \\
\hline 4 & Core Fuel Weight (U) & 159.93 & MTM \\
\hline 5 & Thermal Efficiency & 0.3361 & -- \\
\hline 6 & Design Capacity Factor & 0.7779 & -- \\
\hline 7 & Assembly Rod Array & $8 \times 8$ & -- \\
\hline 8 & Rod Pitch & 1.6256 & $\mathrm{~cm}$ \\
\hline 9 & Pellet Density & 95 & $\%$ Theo. \\
\hline 10 & Pellet Diameter & 1.0566 & $\mathrm{~cm}$ \\
\hline 11 & Fuel Rod Outer Diameter & 1.2522 & $\mathrm{~cm}$ \\
\hline 12 & Clad Thickness & 0.08636 & $\mathrm{~cm}$ \\
\hline 13 & Reload Batch Size & 0.2500 & Core Fraction \\
\hline
\end{tabular}

Two postirradiation storage facilities are modeled. The first of these is assumed to be located at the reactor; the second is located "elsewhere."

The reprocessing plant is assumed to separate the spent fuel composition into uranium, plutonium and the residual radionuclides. This latter category is referred to as rad waste. The separation is done with an input efficiency factor for uranium and plutonium. For example, if an efficiency factor of $99.5 \%$ is specified for plutonium, then $0.5 \%$ of each plutonium isotope goes into rad waste.

The rate at which reprocessing plants can be built is controlled in various ways. If there are no reprocessing plants, the spent fuel is stored until the plants begin operation. The backlog of spent fuel is worked off on a first-in, first-out (FIFO) basis. The startup date and the designed capacity of each plant can be specified, and this capacity can be reached over a 3-year period in increments also specifiable by the user. If the requested construction schedule causes excessive reprocessing capacity--that is, if there is not 
enough fuel available for reprocessing--then the requested schedule is delayed until the spent fuel supply and reprocessing capacity match. A minimum backlog may also be specified. If the specification of reprocessing plants is not complete, then a reference plant is brought on-line at intervals given by the input to work off the spent fuel backlog.

In ENFORM-I the fuel cycle stops at the end of reprocessing. Waste disposal will be treated by another information system ${ }^{(2)}$ which will use the ENFORM-I data base as input.

\section{THE CHAINS}

The material chains that are currently used in ENFORM-I are shown in Table 4. An ORIGEN case is used for each of these chains to determine the isotopic composition from the reactor through reprocessing. Neutron spectrum and the neutron cross sections are adjusted in the ORIGEN cases until reasonable agreement with measured isotopic data is reached. (3)

The results of each ORIGEN case are stored on tape for a11 808 isotopes in the ORIGEN library. The ORIGEN tapes are then processed by an editor code to produce a compacted disc file which is accessed by the DBG during execution to produce the set of isotopic volumes for the data base.

The restriction to chains of fixed composition leads to some minor approximations in the case of plutonium recycle. However, an interpolation technique has been developed which can deal with variations of detailed fuel batch isotopic composition within the framework of fixed chain compositions. This technique was not implemented in ENFORM-I because the isotopic compositions are accurate for most realistic scenarios. However, it is available as a means of dealing with batch compositions which vary more widely.

A double set of isotopics is used in ENFORM. The primary set represents the oxide fuel pellet; the other represents only the cladding and structural material in the fuel assembly. In the reprocessing plant a partitioning of these two materials occurs at the dissolver. To reflect this partitioning an additional set of template isotopic files is constructed which is accessed 
TABLE 4. ENFORM-I Material Chain Specifications

\begin{tabular}{|c|c|c|c|c|}
\hline $\begin{array}{l}\text { Cha in } \\
\text { Number }\end{array}$ & Reactor & $\begin{array}{l}\text { Enrichment } \\
\text { w/o Fissile }\end{array}$ & $\begin{array}{l}\text { Discharge } \\
\text { Exposure } \\
\text { MWD/MTM }\end{array}$ & Description \\
\hline 1 & PWR & 2.00 & 15000 & First Core, Region 1 \\
\hline 2 & PWR & 2.60 & 25000 & 2 \\
\hline 3 & PWR & 3.10 & 33000 & 3 \\
\hline 4 & PWR & 3.20 & 33000 & First Reload \\
\hline 5 & PWR & 3.20 & 33000 & Equilibrium Reload \\
\hline 6 & BWR & 1.70 & 10000 & First Core, Batch 1 \\
\hline 7 & BWR & 1.90 & 17000 & 2 \\
\hline 8 & BWR & 1.90 & 20000 & 3 \\
\hline 9 & BWR & 1.90 & 21000 & 4 \\
\hline 10 & BWR & 2.70 & 26000 & First Reload \\
\hline 11 & BWR & 2.60 & 27000 & Equilibrium Reload \\
\hline 12 & PWR & 3.55 & 33000 & First Uranium Recycle \\
\hline 13 & PWR & 4.73 & 33000 & Second Uranium Recycle \\
\hline 14 & PWR & 9.09 & 33000 & Third Uranium Recycle \\
\hline 15 & BWR & 2.88 & 27000 & First Uranium Recycle \\
\hline 16 & BWR & 3.83 & 27000 & Second Uranium Recycle \\
\hline 17 & BWR & 7.43 & 27000 & Third Uranium Recycle \\
\hline 18 & PWR & 3.98 & 33000 & First Plutonium Recycle \\
\hline 19 & PWR & 7.08 & 33000 & Second Plutonium Recycl \\
\hline 20 & PWR & 13.00 & 33000 & Third Plutonium Recycle \\
\hline 21 & BWR & 2.78 & 27000 & First Plutonium Recycle \\
\hline 22 & BWR & 3.76 & 27000 & Second Plutonium Recycl \\
\hline 23 & BWR & 6.49 & 27000 & Third Plutonium Recycle \\
\hline
\end{tabular}


during a Pass I execution to produce an additional set of volumes in the data base. This additional set represents the isotopic content of the structural material and its neutron activation products.

Uranium Recycle

The neutron reactivity penalty associated with the buildup of the ${ }^{236} \mathrm{U}$ isotope is assumed to be compensated by an increased feed enrichment requirement. In principle, determining the final ${ }^{235} \mathrm{U}$ concentration for each batch of uranium available to recycle is an iterative process. ENFORM-I uses a $236_{U}$ penalty of 0.3 weight percent $(\mathrm{w} / \mathrm{O})$ additional ${ }^{235} \mathrm{U}$ for each $1.0 \mathrm{w} / 0{ }^{236} \mathrm{U}$. (4) Because the enrichment process changes the amount of ${ }^{234} U$ and ${ }^{236} U$ in a predictable way, the product material will not reflect this ${ }^{236} \mathrm{U}$ penalty exactly. It is thus necessary to repeat the process with a slightly higher concentration of ${ }^{235} U$ and to continue the process until the cascade product reflects the correct ${ }^{236} \mathrm{U}$ penalty in the fissile composition. In practice, the process converges very rapidly within 15 iterations.

When reprocessing starts before the beginning of recycle, the uranium pool from which the recycle material is drawn is worked off on a FIFO basis. Both the beginning of reprocessing and the beginning of recycle can be specified independently.

Once a beginning date for recycle is specified, then all available uranium is sent into successive recycles until the third recycle pass is reached. At present, recycle stops at the completion of the third recycle. The material discharged from the third recycle is stored.

The extent of recycle can be controlled by specifying a fraction of available uranium for recycle. Material not thus earmarked for recycle is stored. Plutonium Recycle

The overall control of plutonium recycle is much the same as for uranium recycle. That is, the amount of plutonium from reprocessing that is available for recycle is specified and the rest is stored. The date for the start of recycle at the reactors can also be specified. 
The fissile content is determined by weighting the discharge composition of each chain in the batch by the relative amount of material in the chain. When the fissile content of the batch is established, the material is diluted with natural uranium until the input fissile concentration of the chain is reached.

The decay of ${ }^{241} \mathrm{Pu}$ to ${ }^{241} \mathrm{Am}$ occurs with a $215-\mathrm{yr}$ half-life. The fissile content of the plutonium can therefore decrease by a significant amount depending on the time elapsed from reprocessing to recycle. In determining the uranium dilution of the MOX fuel that occurs at the MOX fabrication facility, the decay of ${ }^{241} \mathrm{Pu}$ is calculated from reprocessing to the quarter (year) that it is charged into the reactor. Thus, it always arrives at the reactor with the correct fissile content.

There is no "cross fertilization" of either uranium or plutonium between BWR and PWR; BWR plutonium is recycled only in BWRs and PWR plutonium only in PWRs. This also applies to the uranium. 


\section{FUEL CYCLE COST}

The total cost of each processing stage in the fuel cycle is computed using the NUCOST $(4, \mathrm{pp}$. VIII-19 and XI-8) computer code which was made into a subroutine in the ENFORM-I system.

For each Pass I scenario, the code calculates a cost report for the nonrecycle case, then for the recycle case, and finally a report which shows the difference between the two cases. Every Pass I report has available both a nonrecycle and a recycle material distribution. If recycle is requested, little additional time is needed to provide a difference table which states the economic incentive for the recycle scenario specified.

The component unit cost factors are described in Table 5. The "plutonium price" is a unit price for fissile plutonium assuming that fissile plutonium is sold on a market which is external to the LWR economy. The LMFBR is the most likely external market of course. The sales of plutonium act as a negative cost which reduces the final levelized power cost.

A final levelized power cost in mills per kilowatt hour is provided at the end of each yearly cost table. The nonrecycle case is always assumed to be the base case and so its cost is subtracted from the recycle case cost in forming the difference table. This means that a negative levelized power cost in the difference table is a positive incentive for recycle. 
TABLE 5. Fuel Cycle Unit costs

\begin{tabular}{|c|c|c|c|}
\hline $\begin{array}{c}\text { Item } \\
\text { Number }\end{array}$ & Cost & Units & Form \\
\hline 1 & $\mathrm{U}_{3} \mathrm{O}_{8}$ Charge & $\$ / 1 b$ & yearly schedule \\
\hline 2 & Uranium Conversion & $\$ / \mathrm{kg}-U$ & single value \\
\hline 3 & Separative Work & $\$ /$ SWU & single value \\
\hline 4 & Uranium Fabrication & $\$ / \mathrm{kg}-U$ & single value \\
\hline 5 & Spent Fuel Transportation & $\$ / \mathrm{kg}-\mathrm{HM}$ & yearly schedule \\
\hline 6 & Spent Fuel Storage & $\$ / \mathrm{kg}-\mathrm{HM}-\mathrm{yr}$ & single value \\
\hline 7 & Reprocessing & $\$ / g k-H M$ & yearly schedule \\
\hline 8 & Plutonium Transportation & $\$ / G M-P u$ & single value \\
\hline 9 & Plutonium Storage & $\$ / G M-P u-y r$ & single value \\
\hline 10 & Mixed Oxide Fabrication & $\$ / \mathrm{kg}-\mathrm{HM}$ & single value \\
\hline 11 & Waste Disposal & $\$ / \mathrm{kg}-\mathrm{HM}$ & single value \\
\hline 12 & Pu Price (negative $\cos t)(a)$ & $\$ / G$ FISS & yearly schedule \\
\hline 13 & Spent Fuel Disposal & $\$ / \mathrm{kg}-\mathrm{HM}$ & single value \\
\hline
\end{tabular}

(a) This assumes that there is a market external to the LWR economy which will absorb the LWR plutonium not used in LWR recycle. Sales to this market reduce LWR power costs. 
IMPLEMENTATION AND CODING

The ENFORM-I system currently operates on a CDC 7600 computer under the control of a Scope 2.1 operating system. It uses a dedicated disc pack of 12 million words maximum storage capacity. A single disc pack can hold three to four complete data bases plus the required isotopics template file. The system spans a time period of 30 years. Increases in the time span will reduce proportionately the number of data base scenarios that can be stored on a disc pack. The running time for the creation of a Pass I data base is generally less than 10 minutes. Typical times for the report writer have not been established.

The subroutines in the data base generator are described briefly in the following sections. The variables are defined in Appendix $C$.

SUBROUTINE BOSS

Subroutine BOSS is the main program. It exerts supervisory control over the calculation and calls the other major subroutines.

SUBROUTINES FILIN, FILOUT, RDWTDS

These are the primary input-output routines that control the storage and retrieval of information on the disc pack. RDWTDS is the primary I/0 routine; it does the bookkeeping on calls to FILIN and FILOUT. As the names imply, these last two routines are read-only and write-only modules.

\section{SUBROUTINES FPP AND FX}

These minor subroutines are used to calculate the decay of ${ }^{241} \mathrm{Pu}$ from discharge to the fabrication of mixed oxide fuel (FPP), and to return the change in ${ }^{234} U$ and ${ }^{236} U$ concentrations in the enrichment plant $(F X)$. 
SUBROUTINE IMP

IMP is the primary input reading subroutine. ENFORM-I uses NAMELIST for all input variables.

SUBROUTINE ISO

The isotopic portion of the data base is written by this subroutine using the isotopic template file and the first volume of the data base, which contains the fuel material mass distribution.

SUBROUTINE KWHR

This subroutine performs the important tasks of examining the inputinstalled nuclear generation capacities and allocating the generated energy to the material chains. It does this by starting up new plants based on the increases in installed capacity and by moving this capacity into the other chains as simulation time passes. Chains involving recycle are not used.

SUBROUTINES MASS, PUREC, UREC

MASS is the most important and complex subroutine. It takes the energy generation allocation produced by subroutine KWHR and calculates the mass of fuel material distributed by chain, process plant, and quarter year. The first pass determines the amount of material available for recycle. On the second pass the requested material is recycled as required and the energy is added to the recycle chains at the expense of the equilibrium chains. If there is not enough equilibrium capacity, a pool is formed and the excess is stored until the next quarter when it is added to the amount to be recycled in that quarter and another check is made against the available equilibrium chain capacity. MASS calls PUREC and UREC respectively for the detailed plutonium and uranium recycle calculations. 


\section{SUBROUTINES SEPRAT AND REPRO}

These subroutines are used to determine the construction schedule for the reprocessing plants.

SUBROUTINE QA

Internal consistency checks of the input numbers are performed by the subroutine QA.

SUBROUTINE SEPWRK

This subroutine calculates the separative work performed in the enrichment plant.

SUBROUTINE SHRINK

SHRINK contracts the quarterly distributions of fuel material to a yearly distribution and writes the first "volume" of the data base.

\section{ACKNOWLEDGMENT}

The authors acknowledge the helpful advice and comments of E. T. Merrill, R. W. McKee, R. M. Fleischman, and T. J. Kabele. Able assistance was provided by R. M. Abraham, M. R. Jantz and W. A. Muckerheide on various aspects of developing the ENFORM-I system. And finally the report was greatly improved by the editorial contributions of L. O. Foley. 


\section{REFERENCES}

1. M. J. Be11, ORIGEN - The ORNL Isotope Generation and Depletion Code. ORNL-4628, Oak Ridge, TN, May 1973.

2. Commercial Waste Management Impact Statement (CWMIS) Currently Underway at Battelle, Pacific Northwest Laboratories. The waste treatment information system is now under development and assumes that ENFORM will form most of its input.

3. C. M. Heeb and E. T. Merri11, Significant Actinide Activities in the LWR and LMFBR Fuel Cycles. EPA-520/3-75-006, October 1974.

4. "Final Generic Environmental Statement on the Use of Recycle Plutonium in Mixed Oxide Fuel in Light Water Cooled Reactors," NUREG-0002, Vol. 4, p. $\operatorname{VIII}(B)-2$. 


\section{APPENDIX A}

\section{DATA BASE GENERATOR SAMPLE CASE}

The short form of the DBG output is given here. The sequence of cases is as follows:

1. Table 1 lists the input scenario.

2. Table 2 gives the reprocessing plant schedule.

3. Table 3 gives the mass flow without recycle.

4. Table 3 gives the mass flow with recycle.

5. Section 1 repeats the mass flows from NUCOST without recycle.

6. Section 2 gives the unit cost assumptions.

7. Section 3 gives total costs without recycle for materials and services.

8. Section 4 gives the fuel cycle cost summary without recycle.

9. Sections 1 through 4 repeat items 4 through 8 above with recycle.

10. This is another repeat of sections 1 through 4 where a difference has been taken between recycle and nonrecycle. Negative costs indicate larger non recycle costs. 
. 


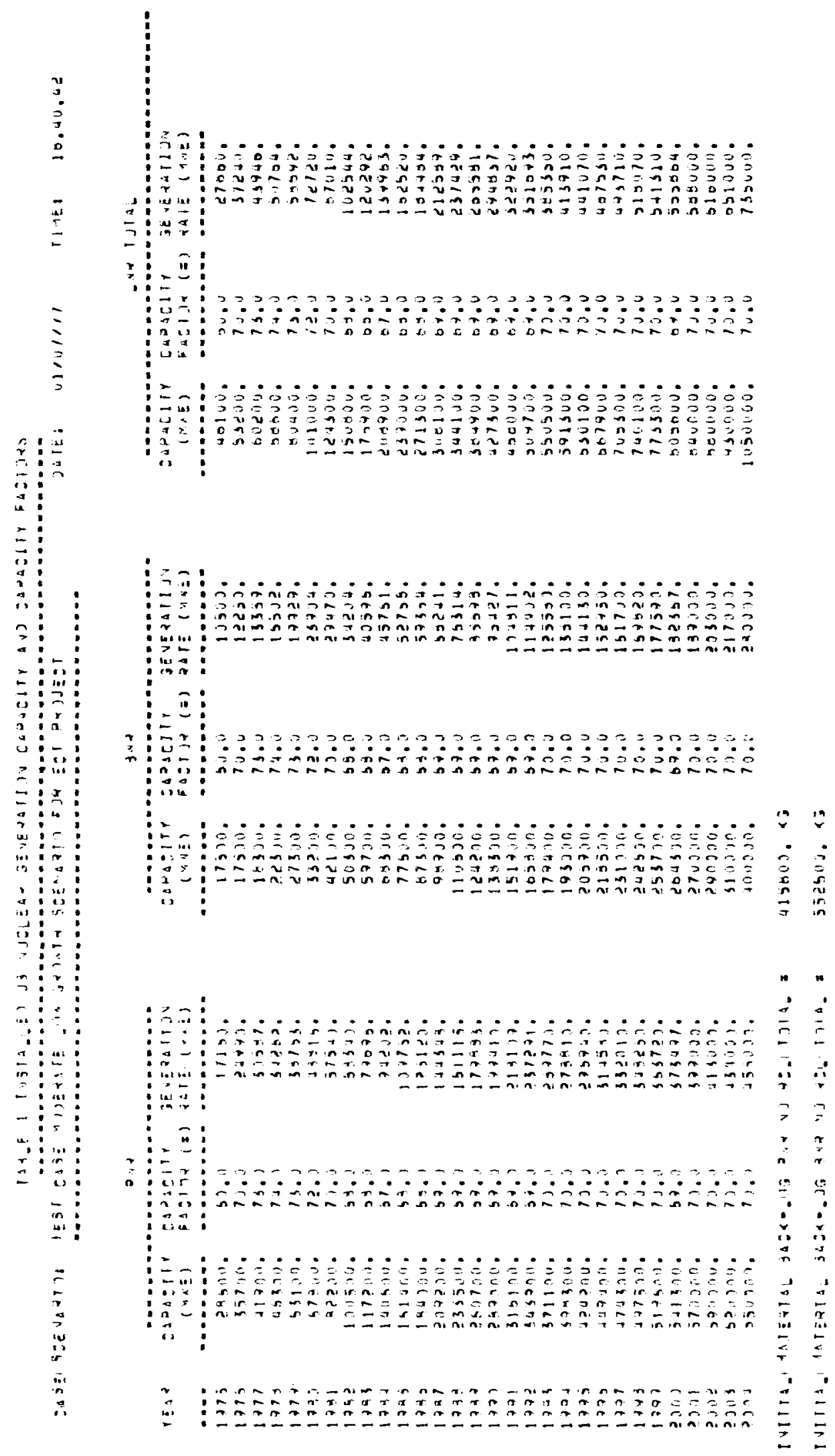




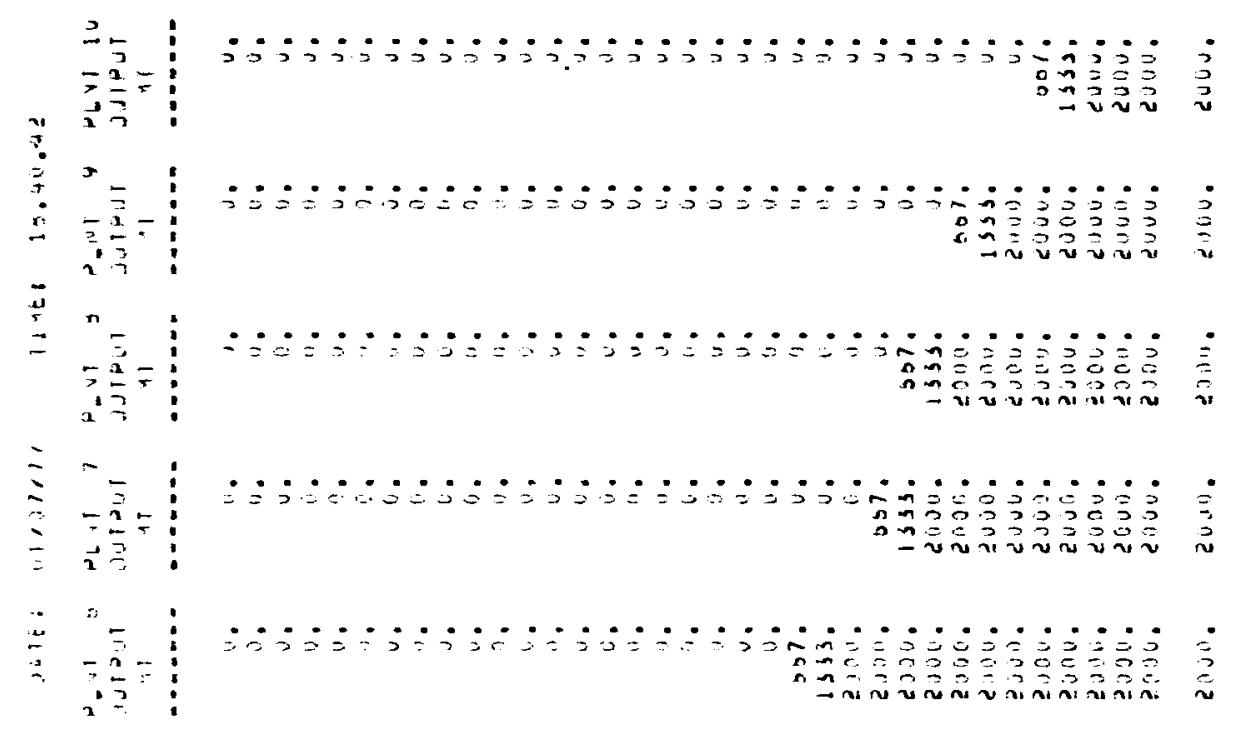

ㅂ.

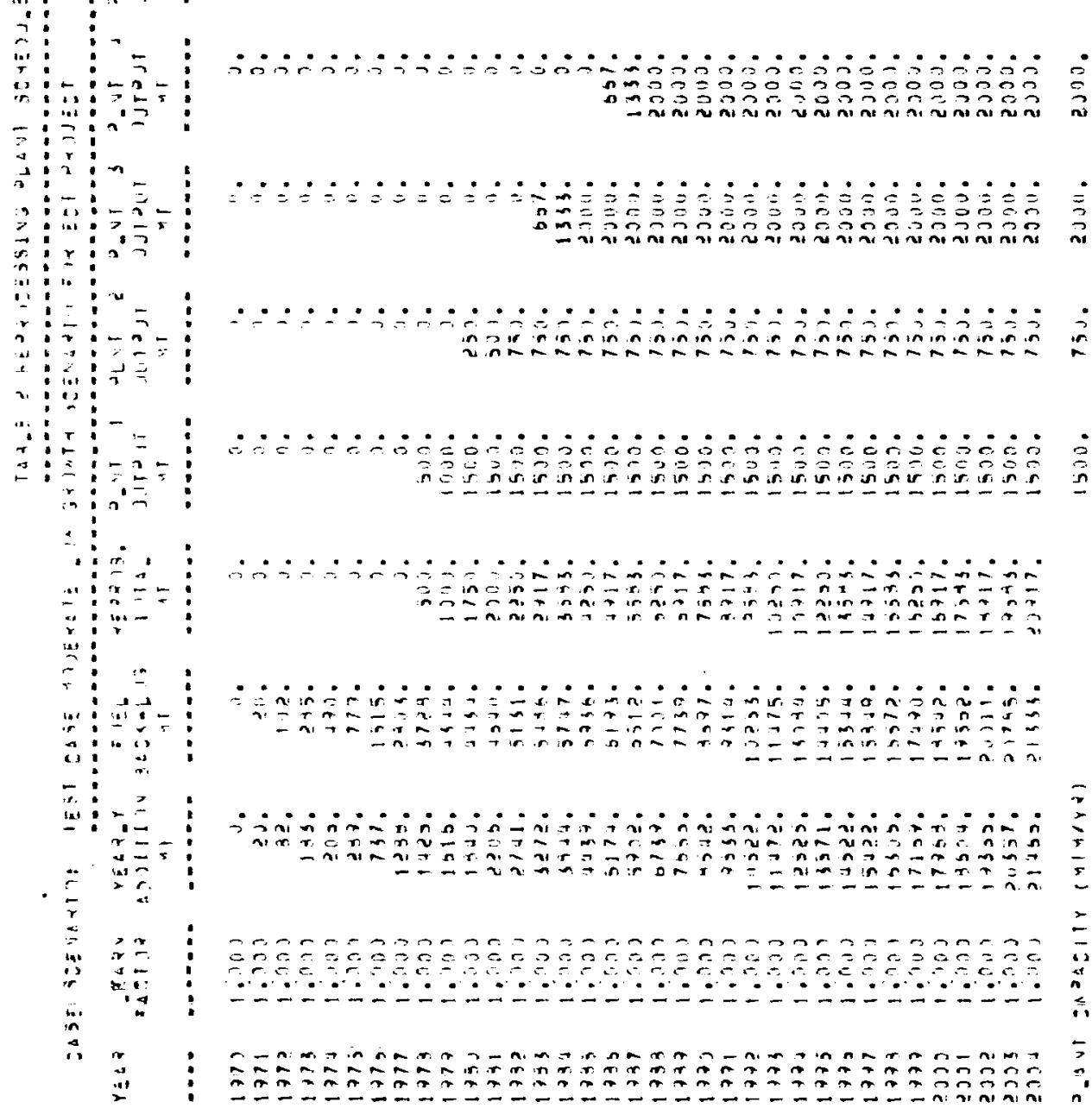




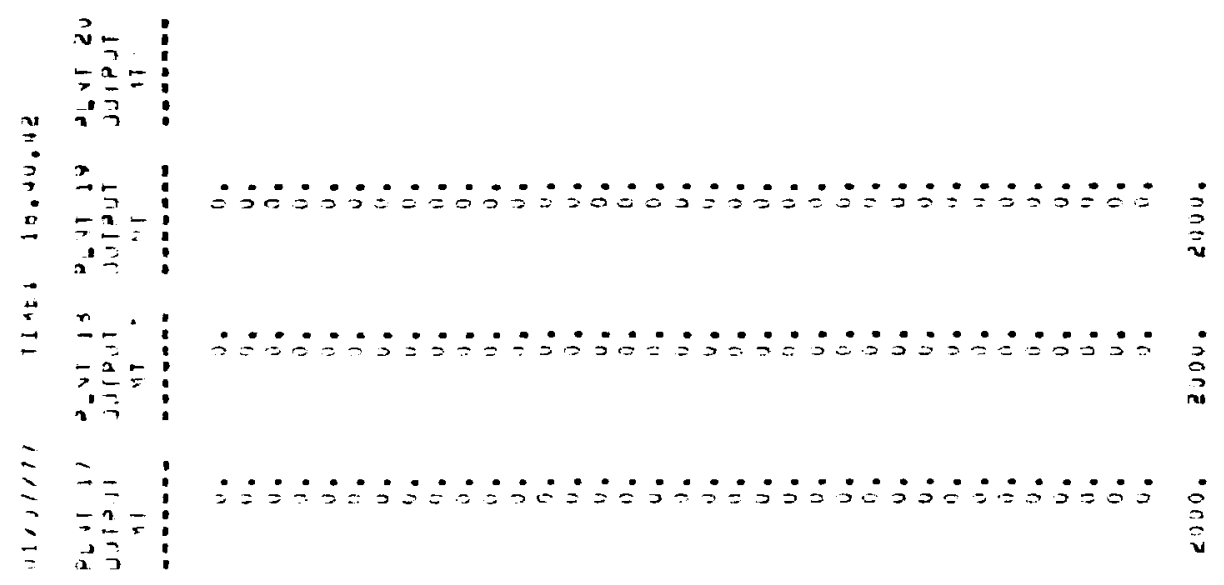

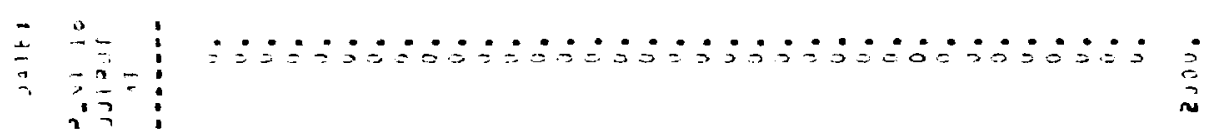



\begin{tabular}{l}
3 \\
\hdashline \\
\hdashline
\end{tabular}

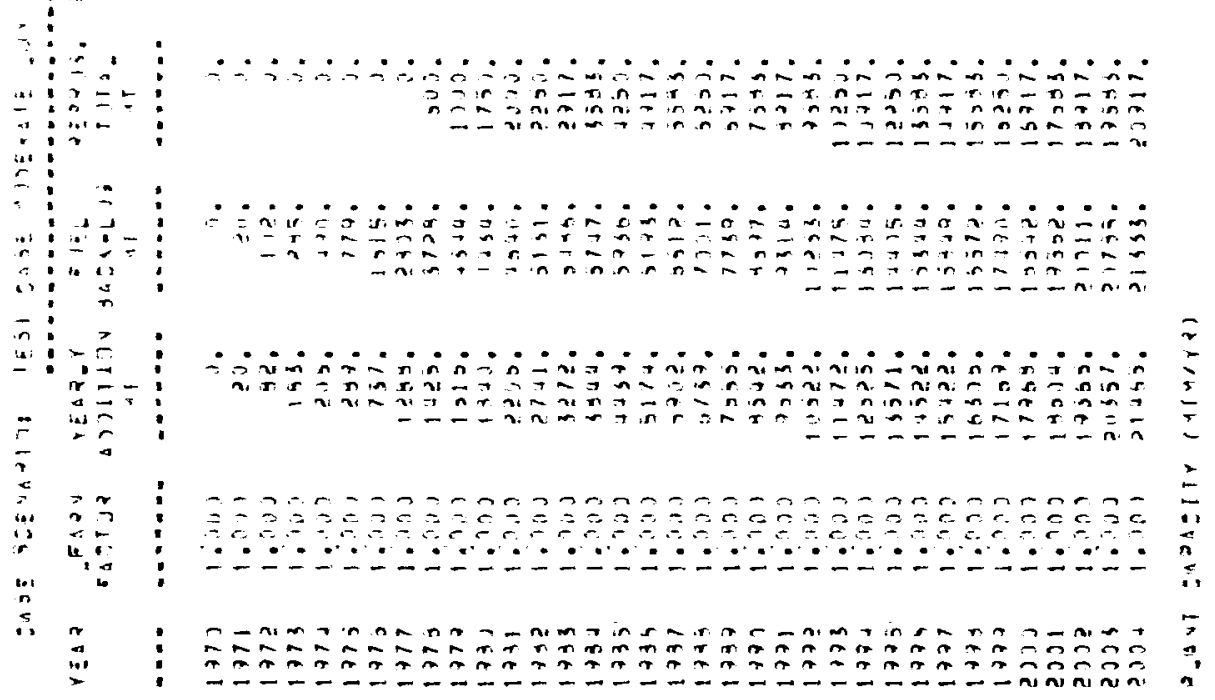




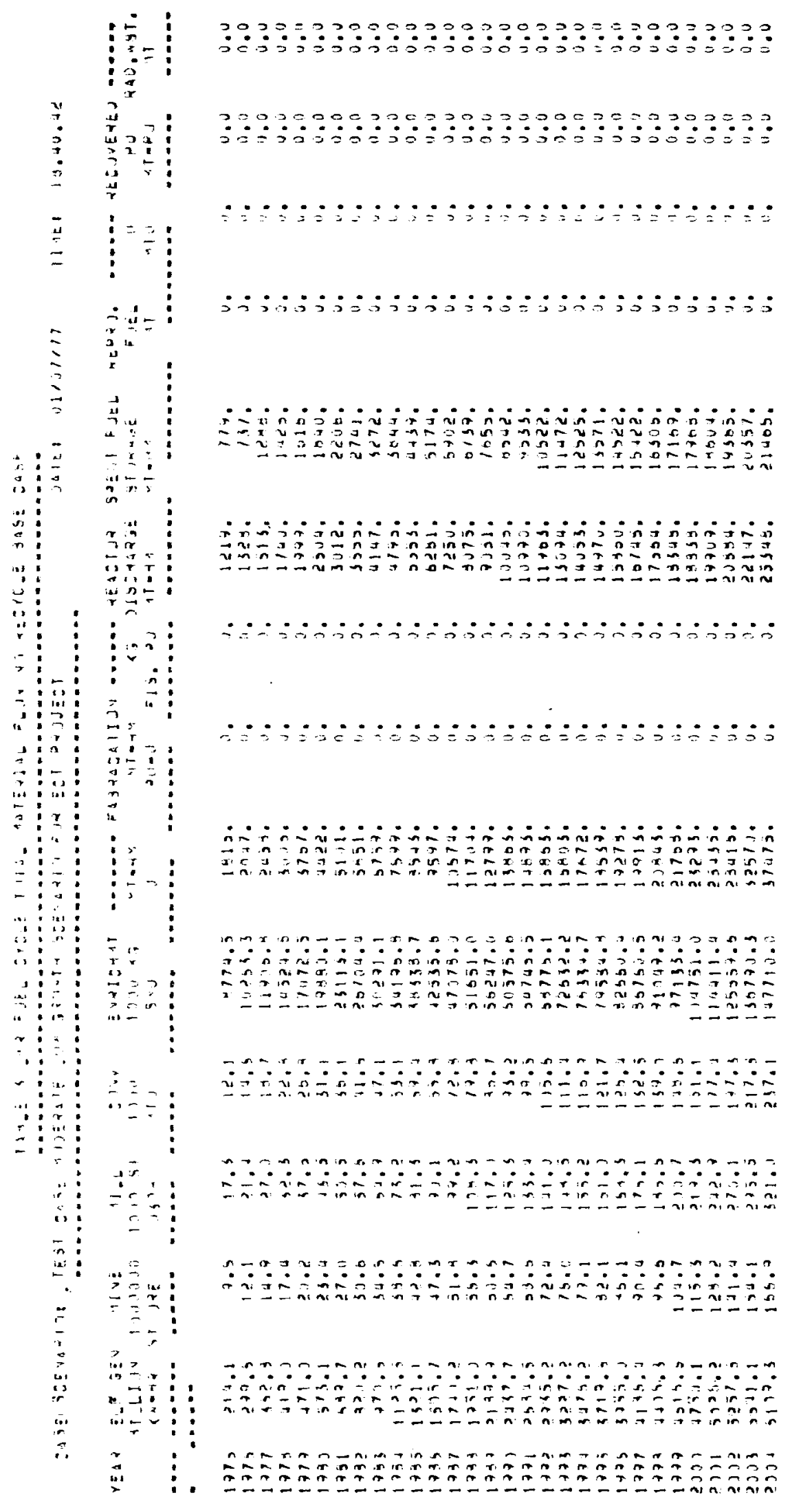




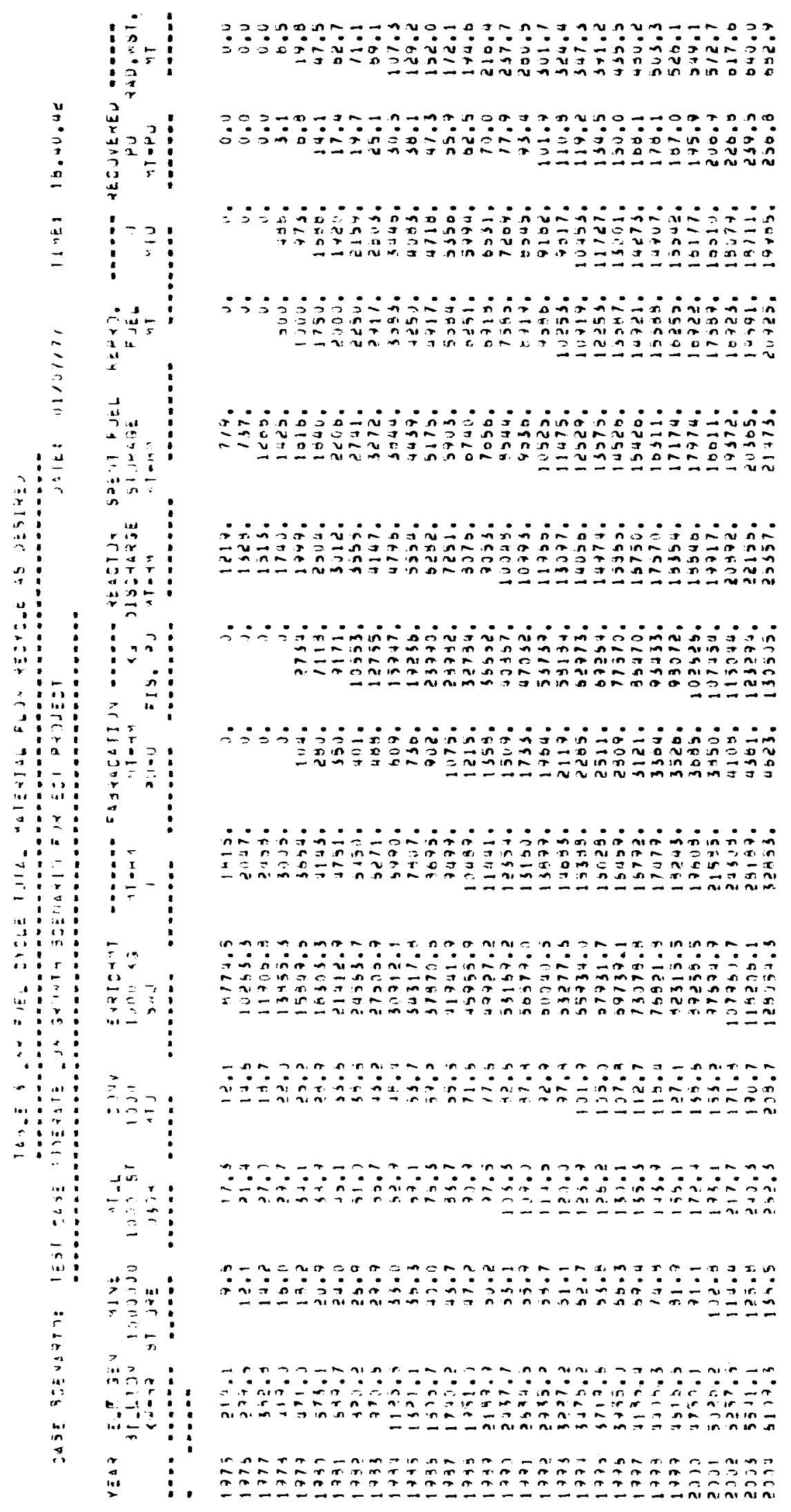




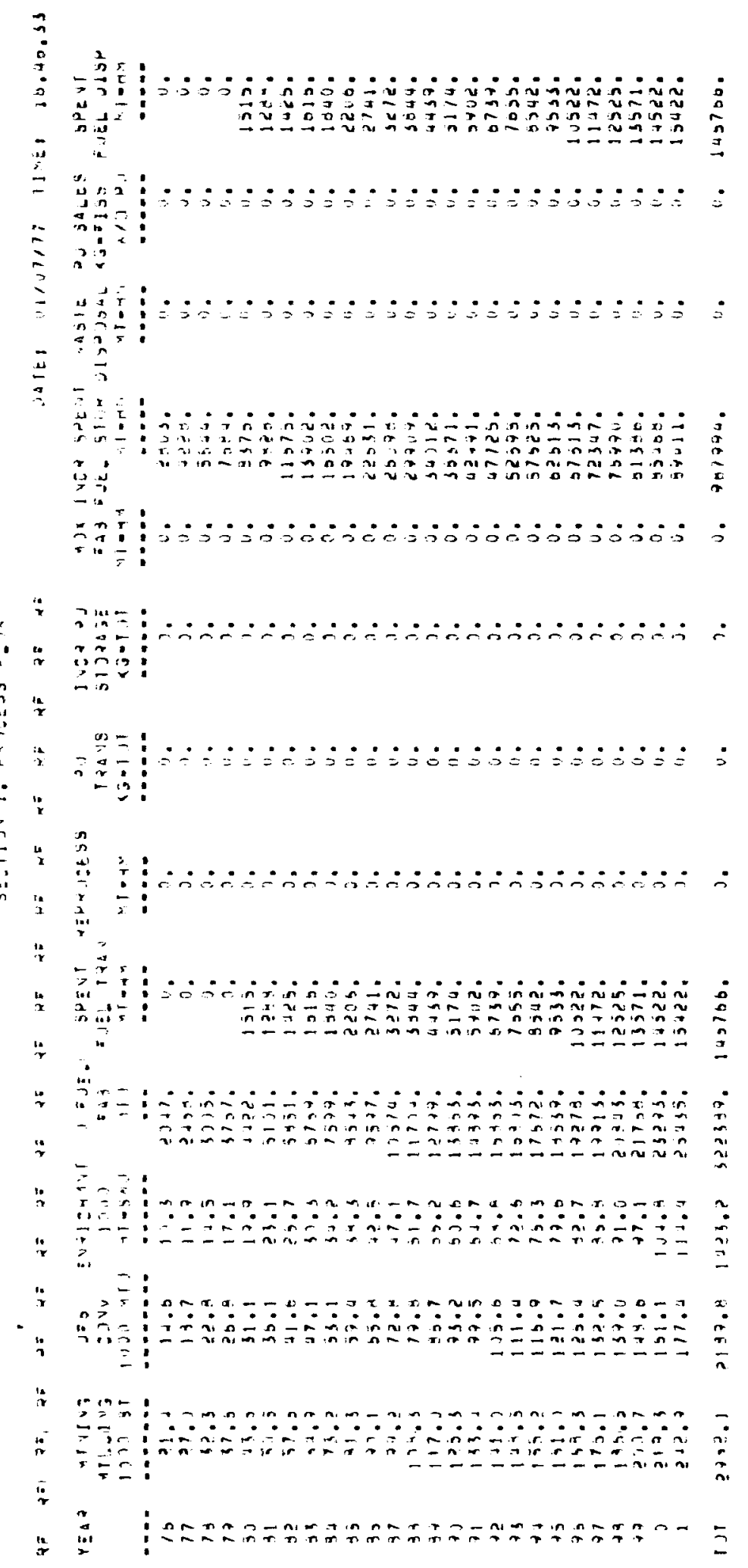




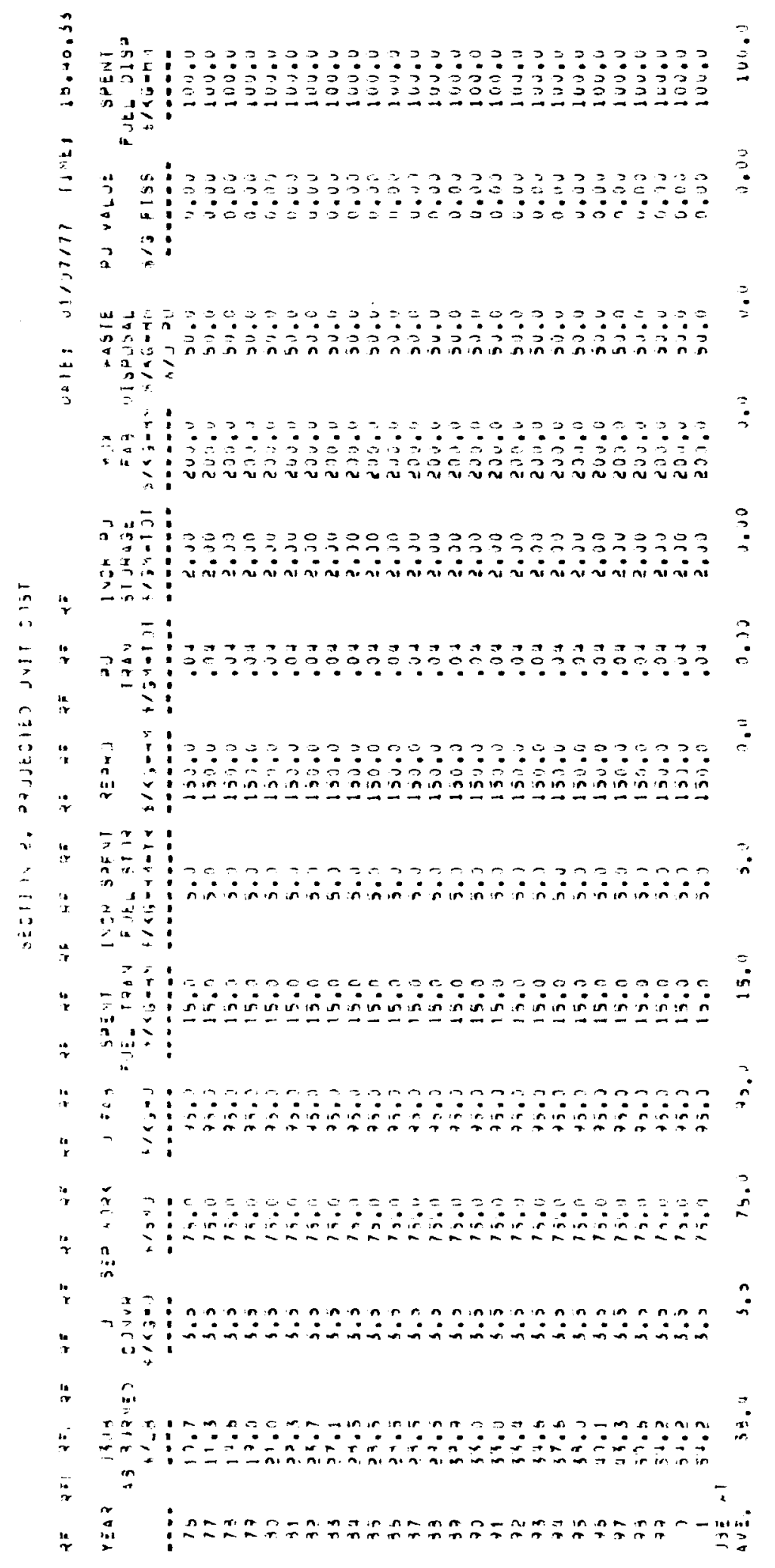




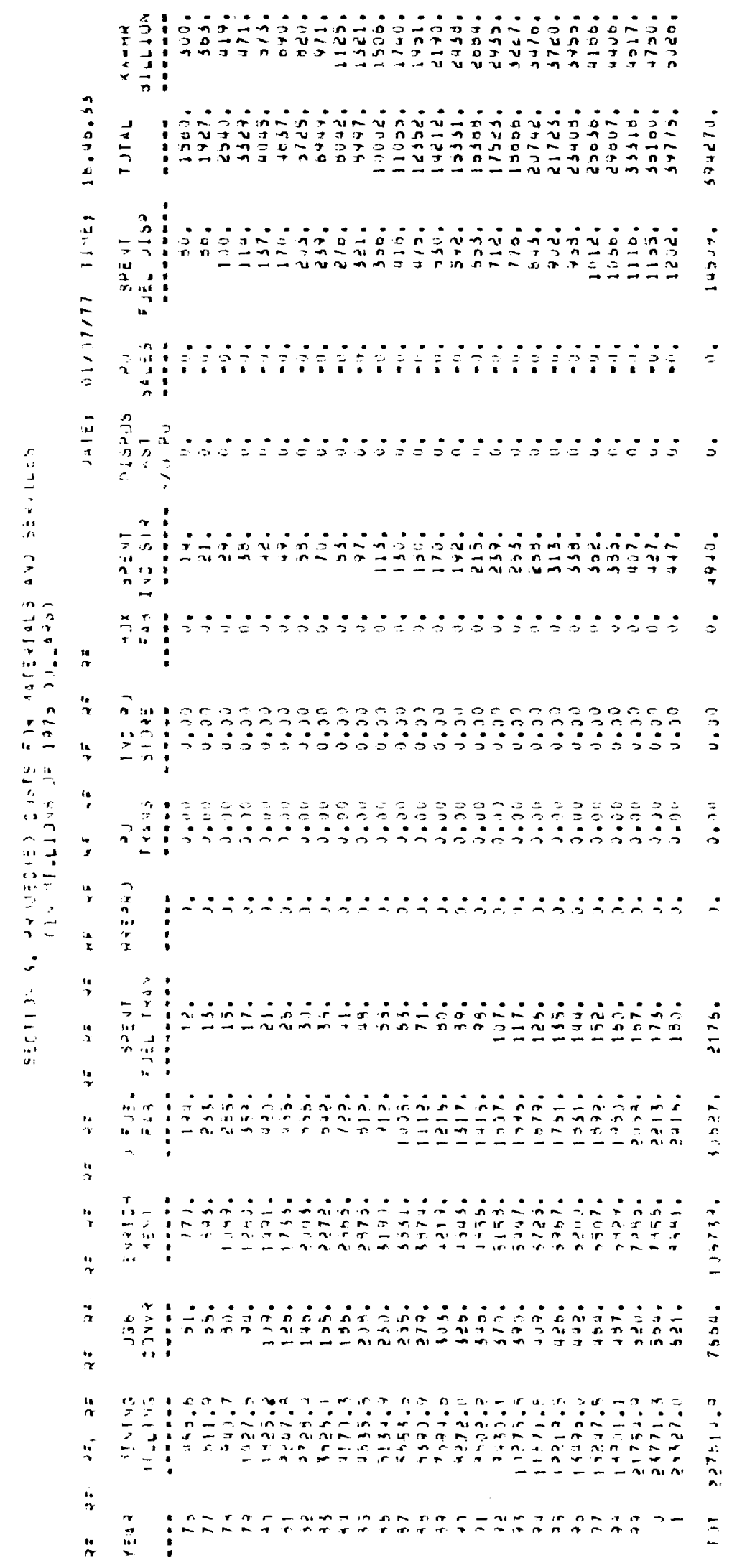




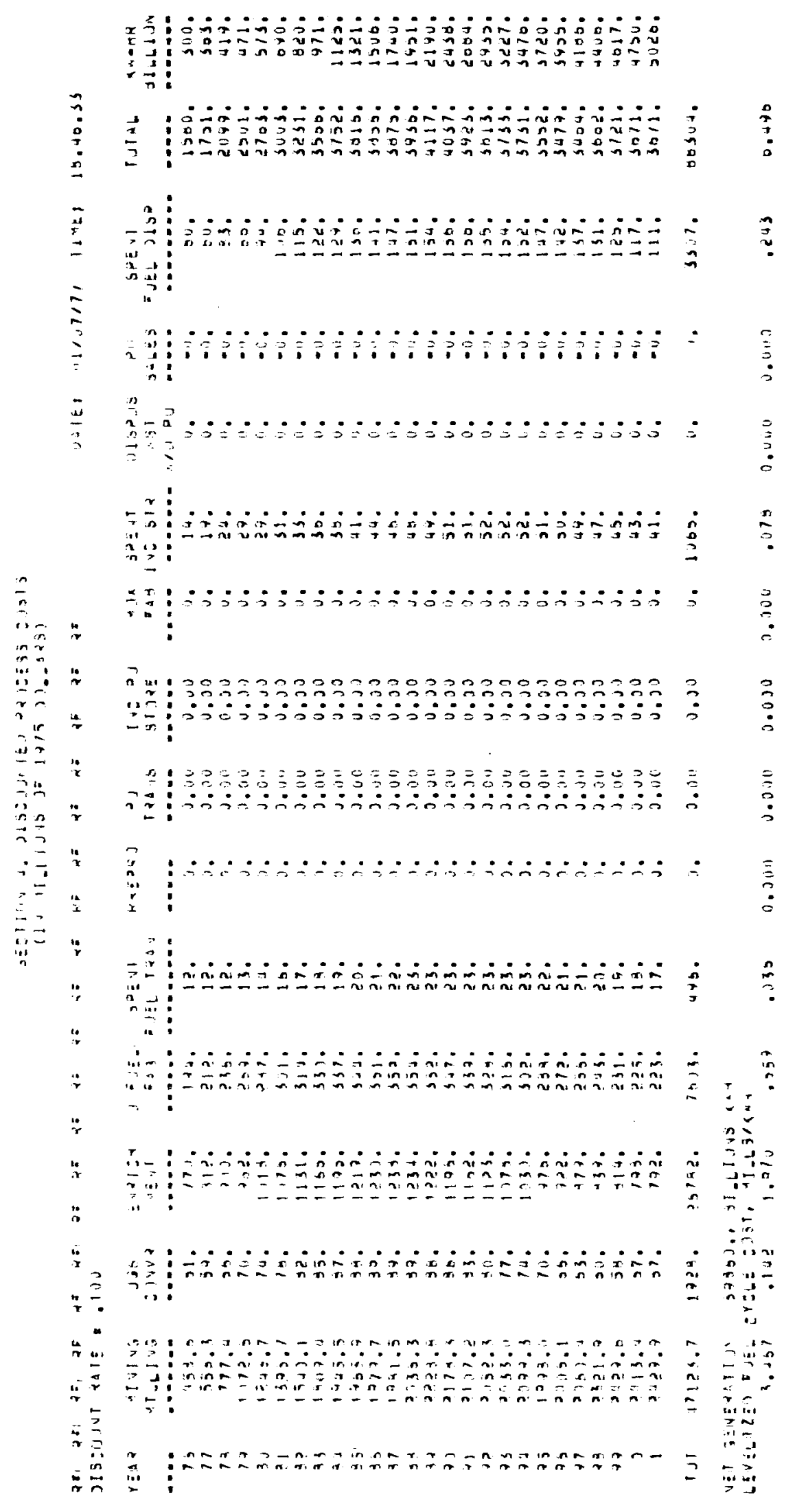




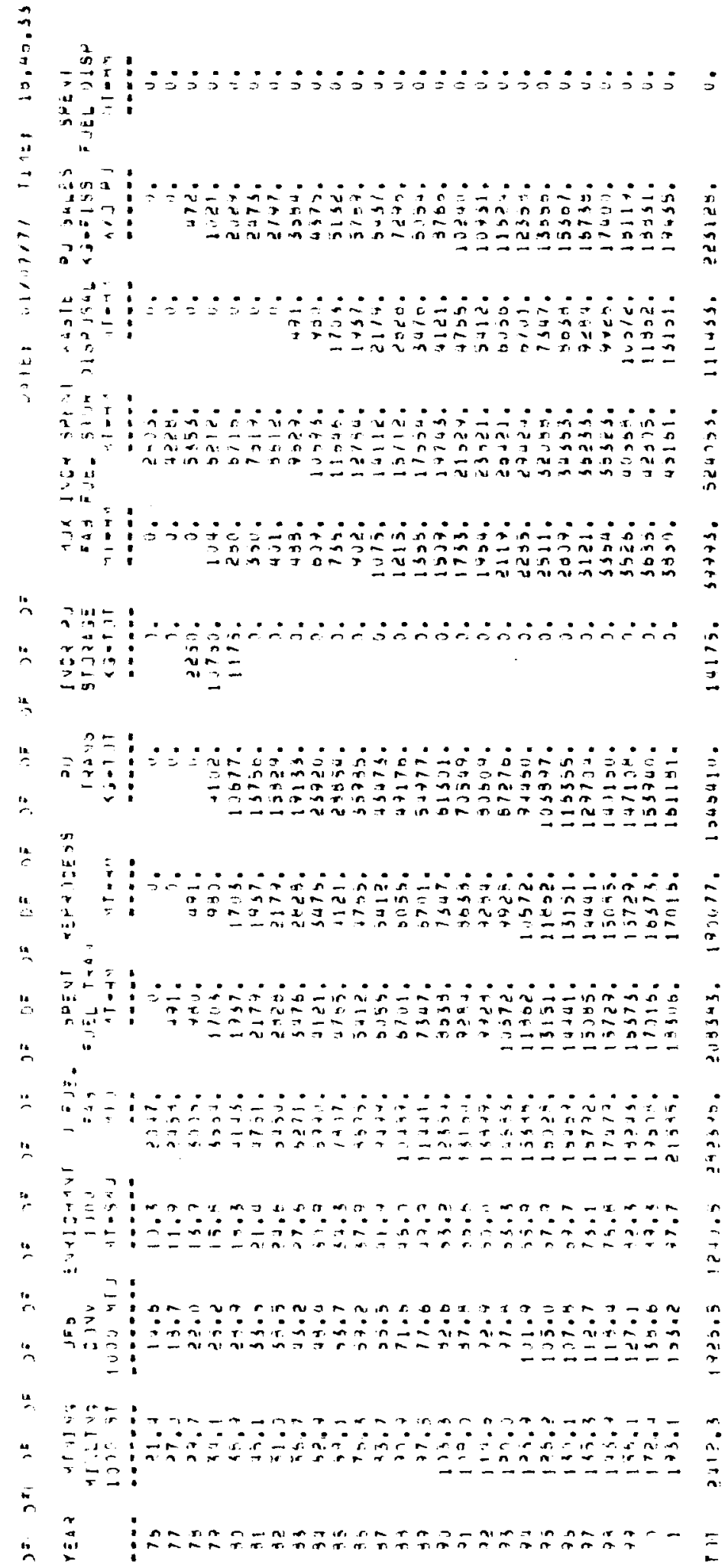




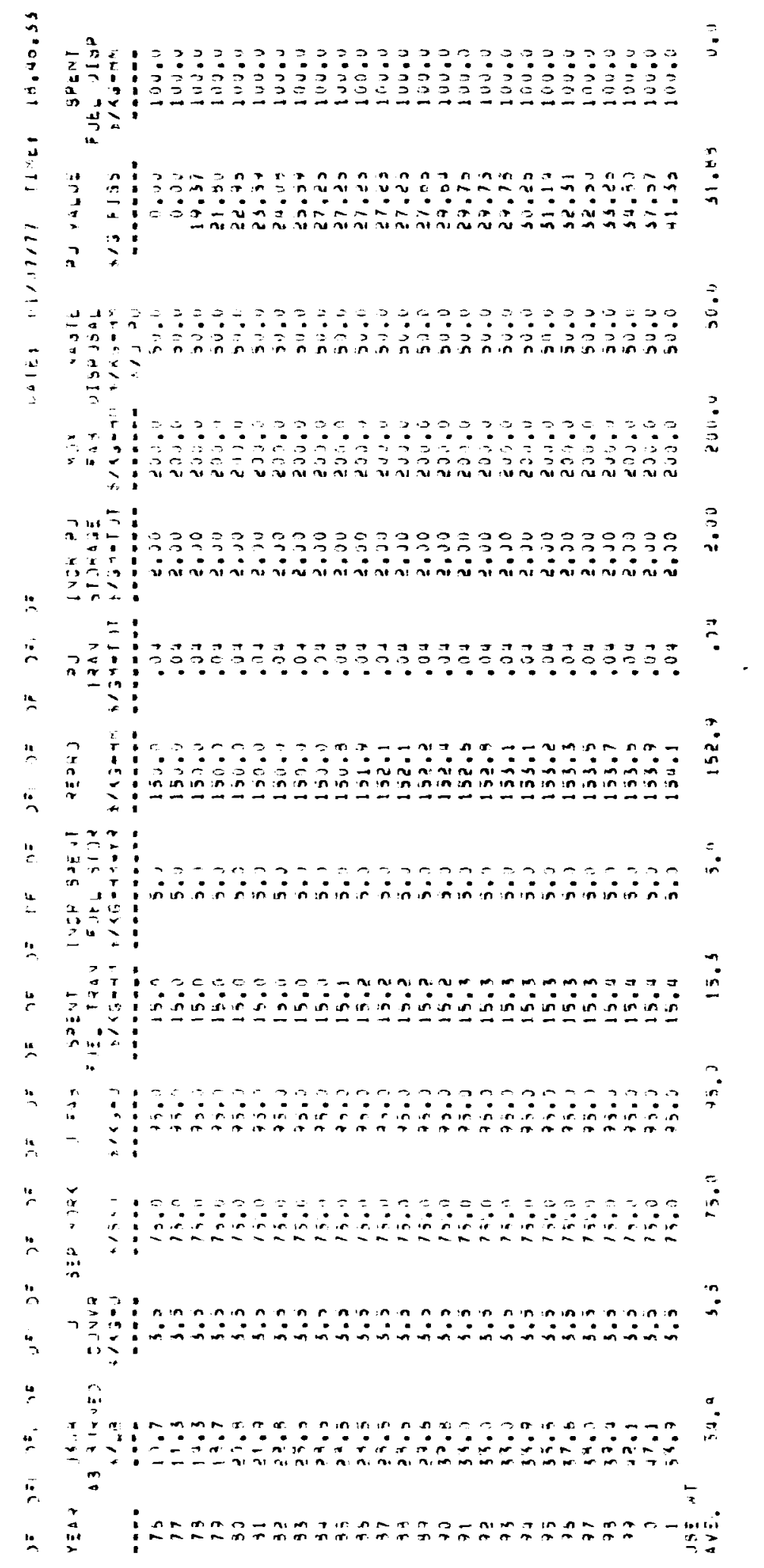




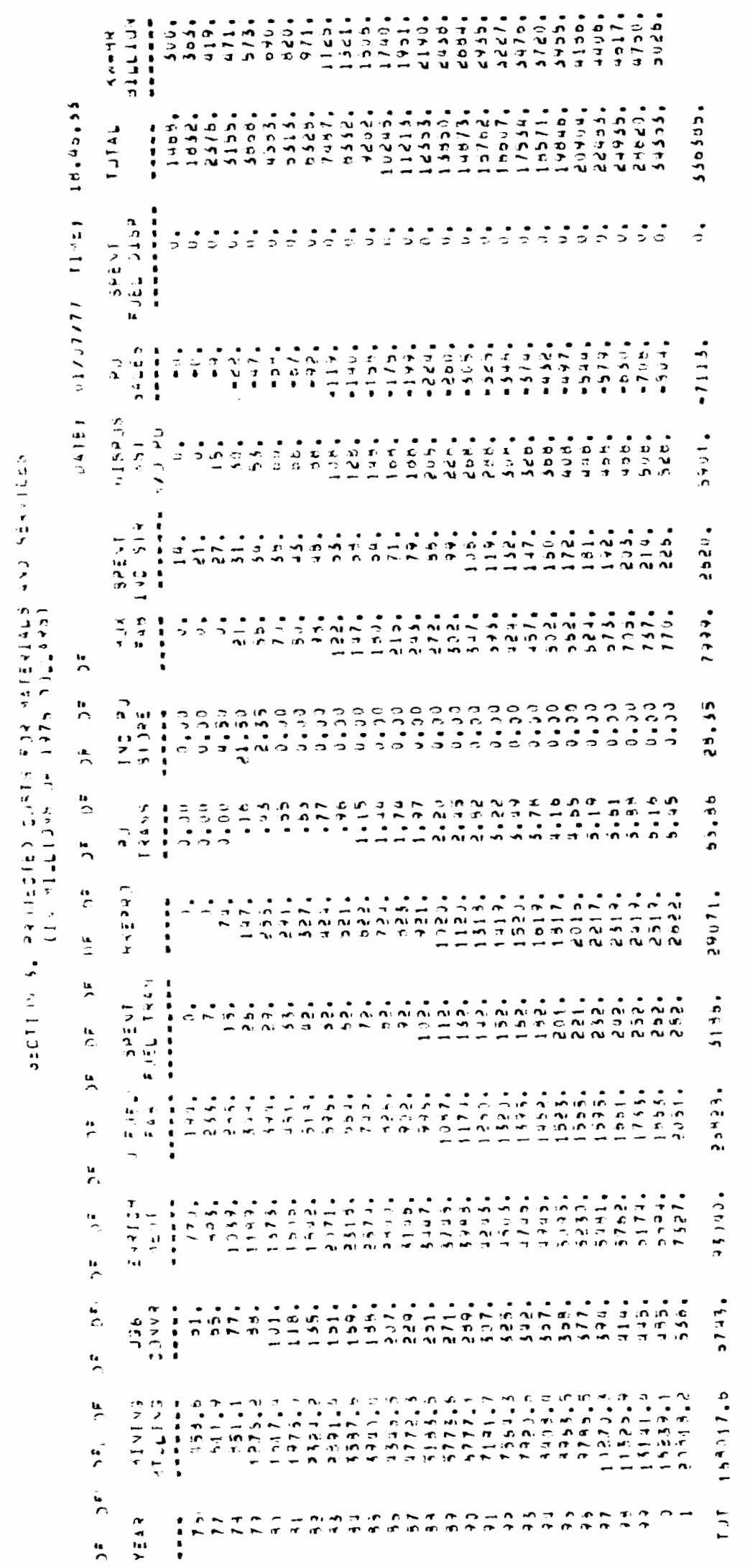




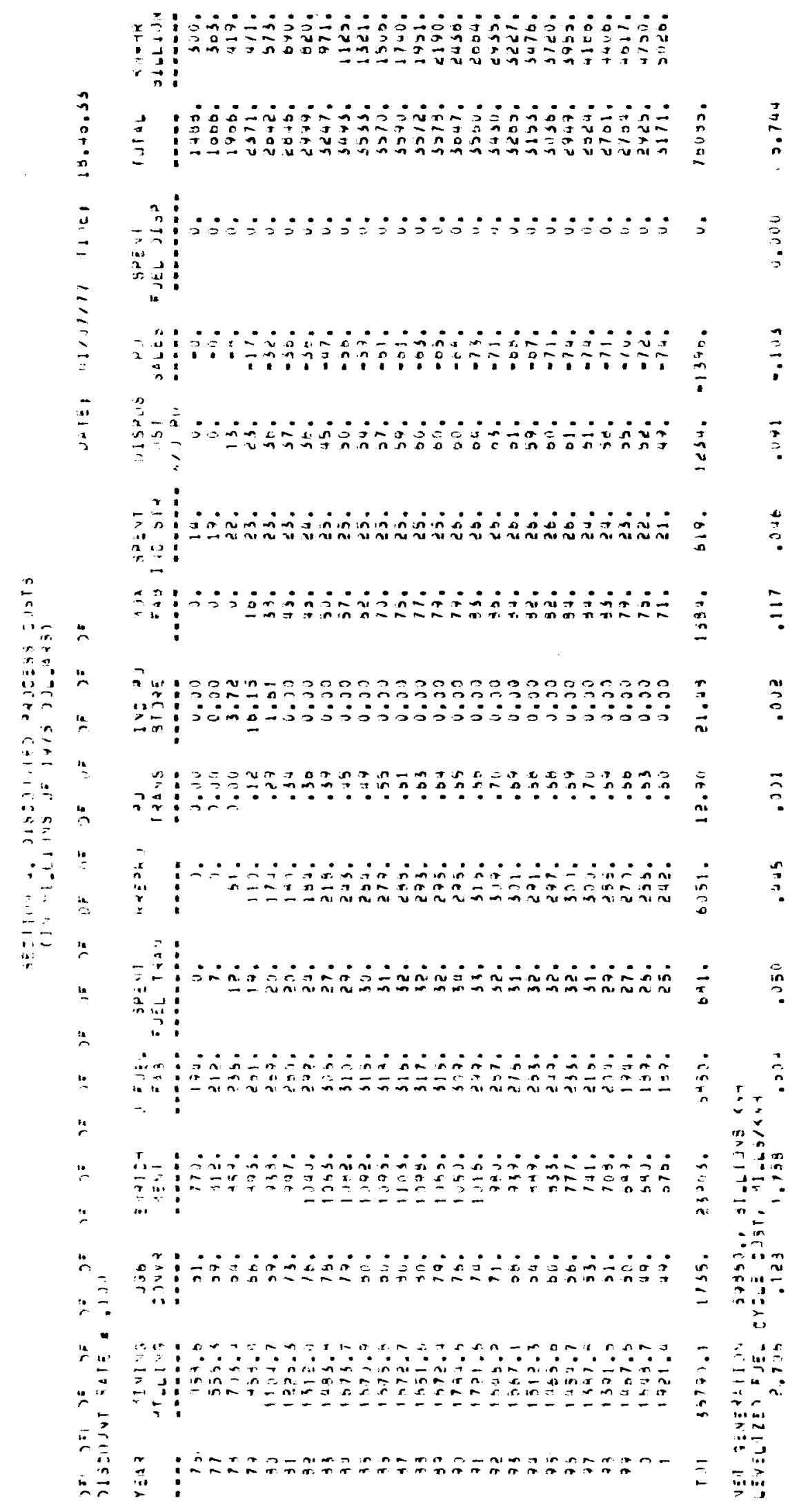




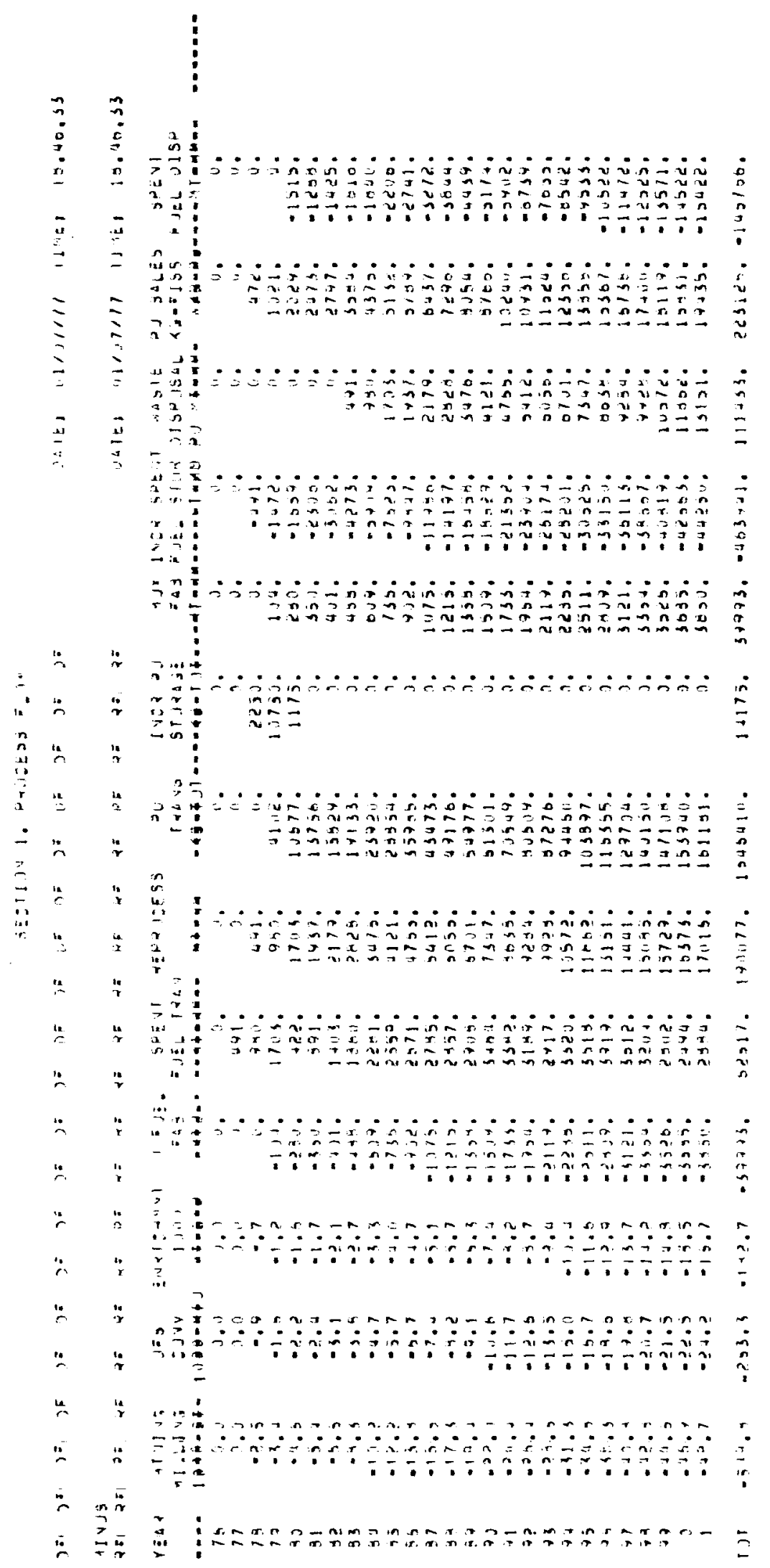




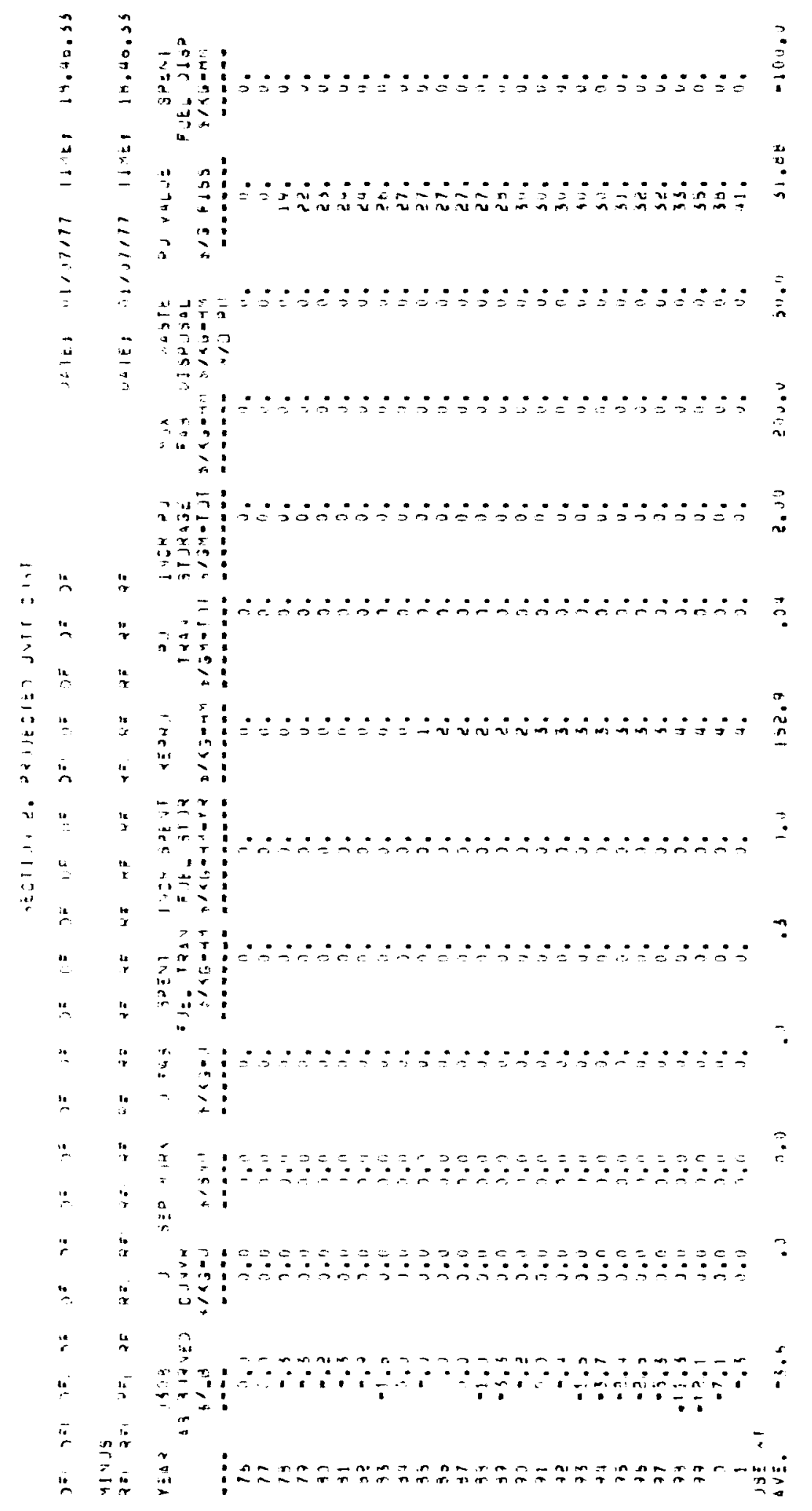




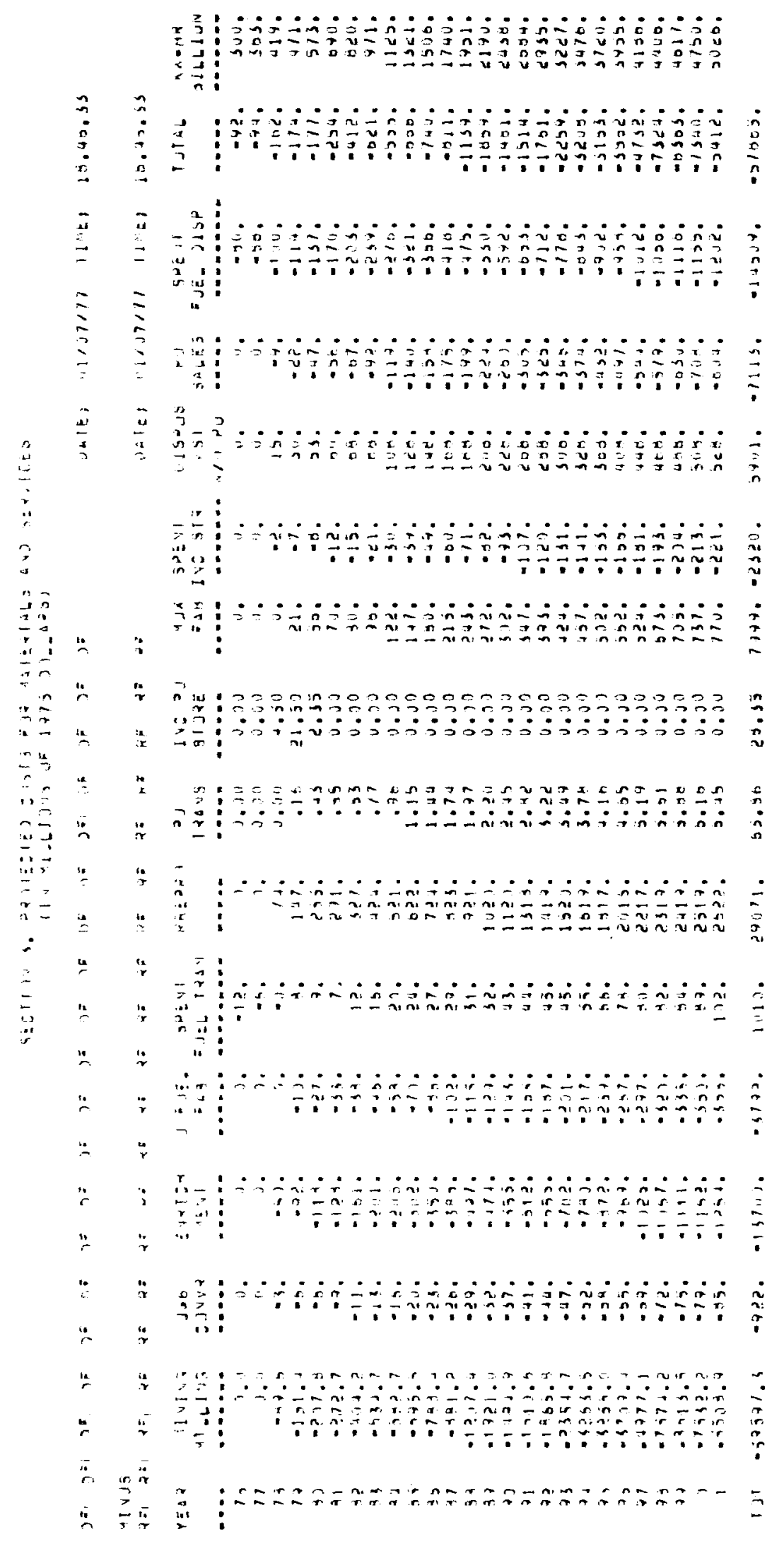




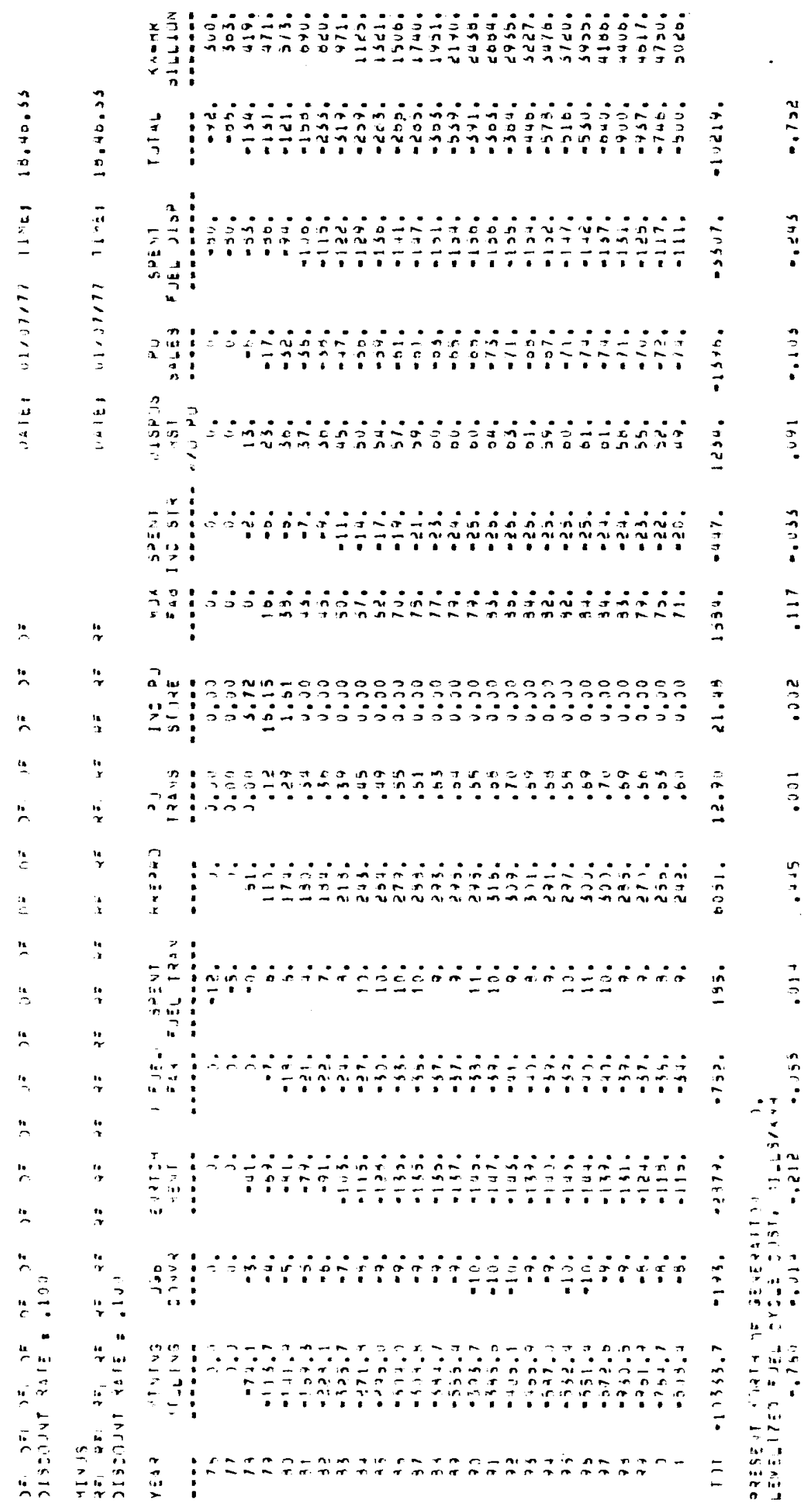




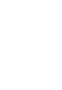


APPENDIX B

\section{REPORT WRITER SAMPLE CASE}

A large number of reports could be generated from the data base using the report writer. The one chosen here is a complete rendering of all chemical effluents by plant. Above the column of numbers is the name of the plant. A double set of columns is printed for each chemical whose name heads the column. "MEDIUM" is the medium to which the chemical is released, i.e., air, water, or as a solid material itself. "QUALITY" refers to the basis of the release factor. A quality number is assigned on a scale of one to three with increasing reliability of the estimate.

Quality

1.0

2.0

3.0

\section{Basis}

Unsubstantiated guess

Calculated or based on laboratory measurements

Based on some plant experience

The numbers contained in the columns are merely debug numbers and do not represent actual chemical effluents.

"TEST CASE" is the name associated with the nuclear power generation scenario used in generating the data base. 


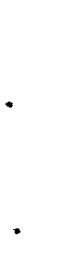



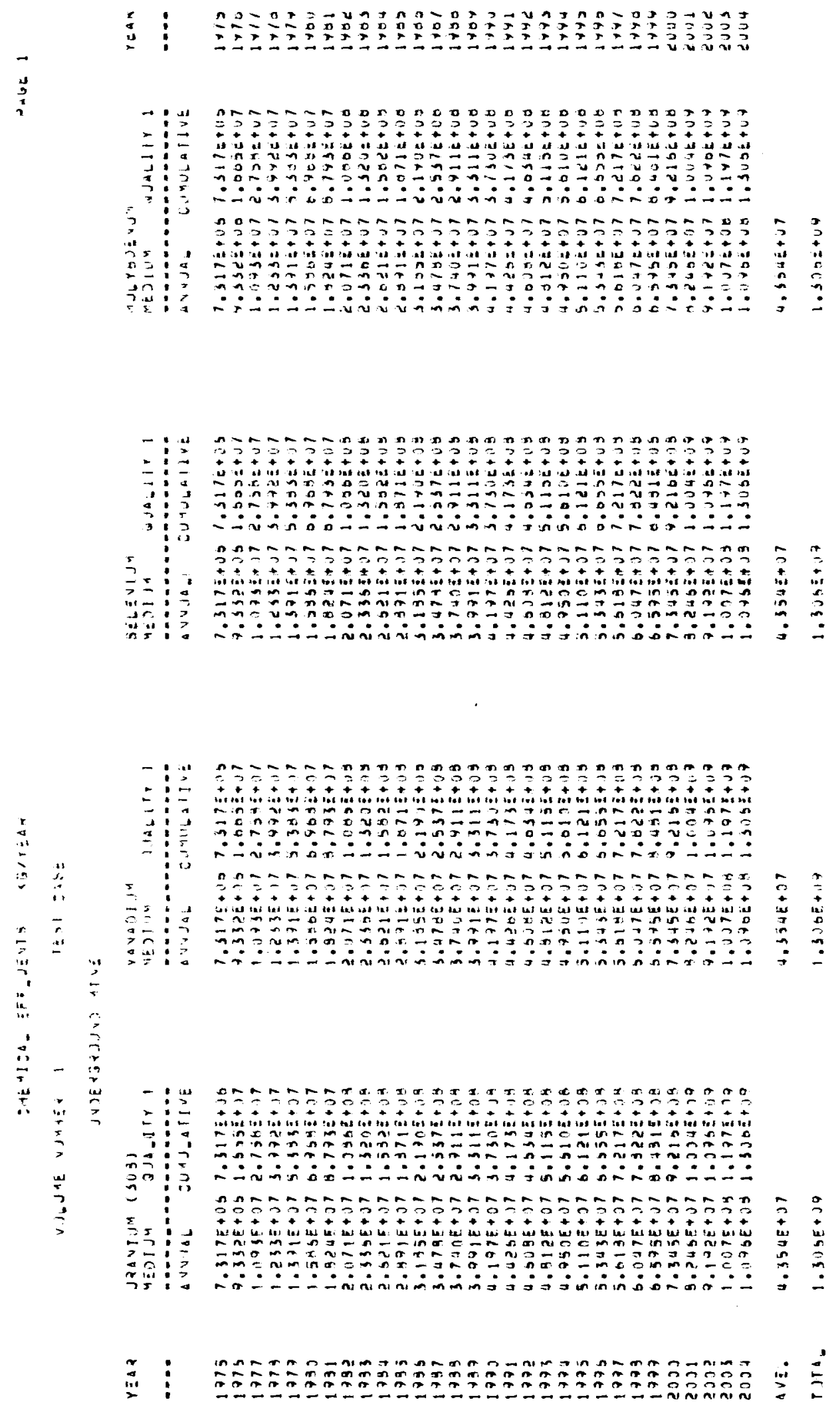

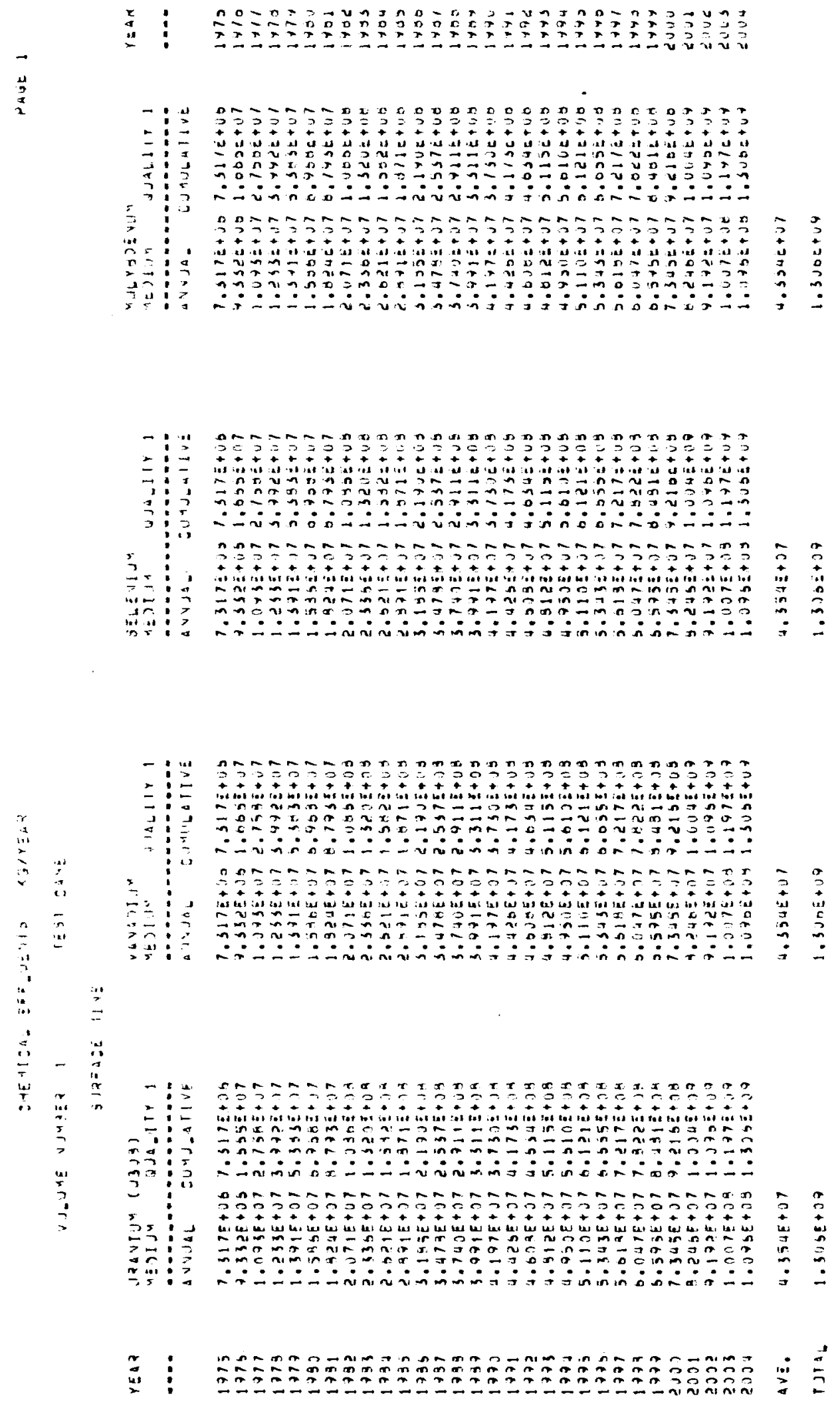

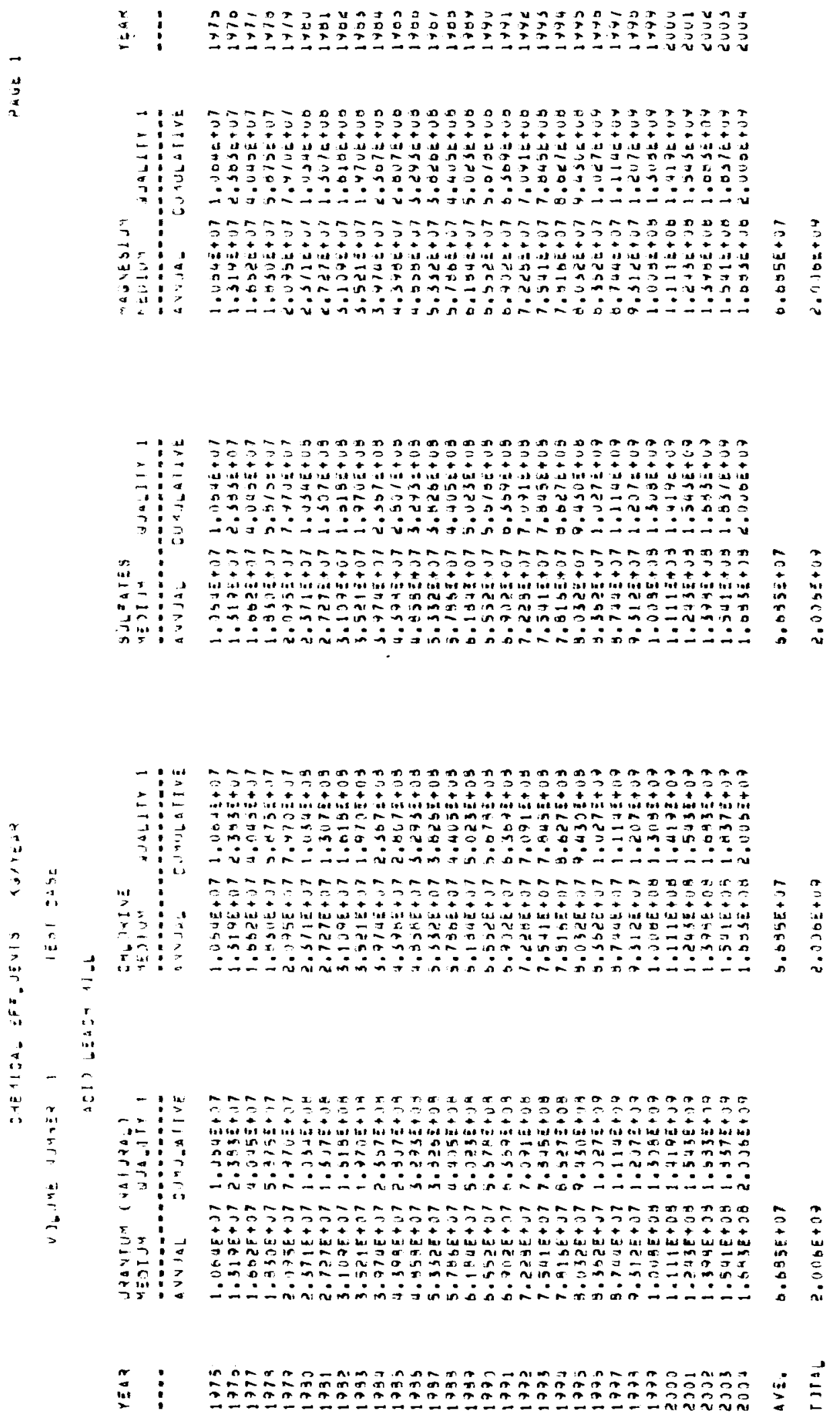

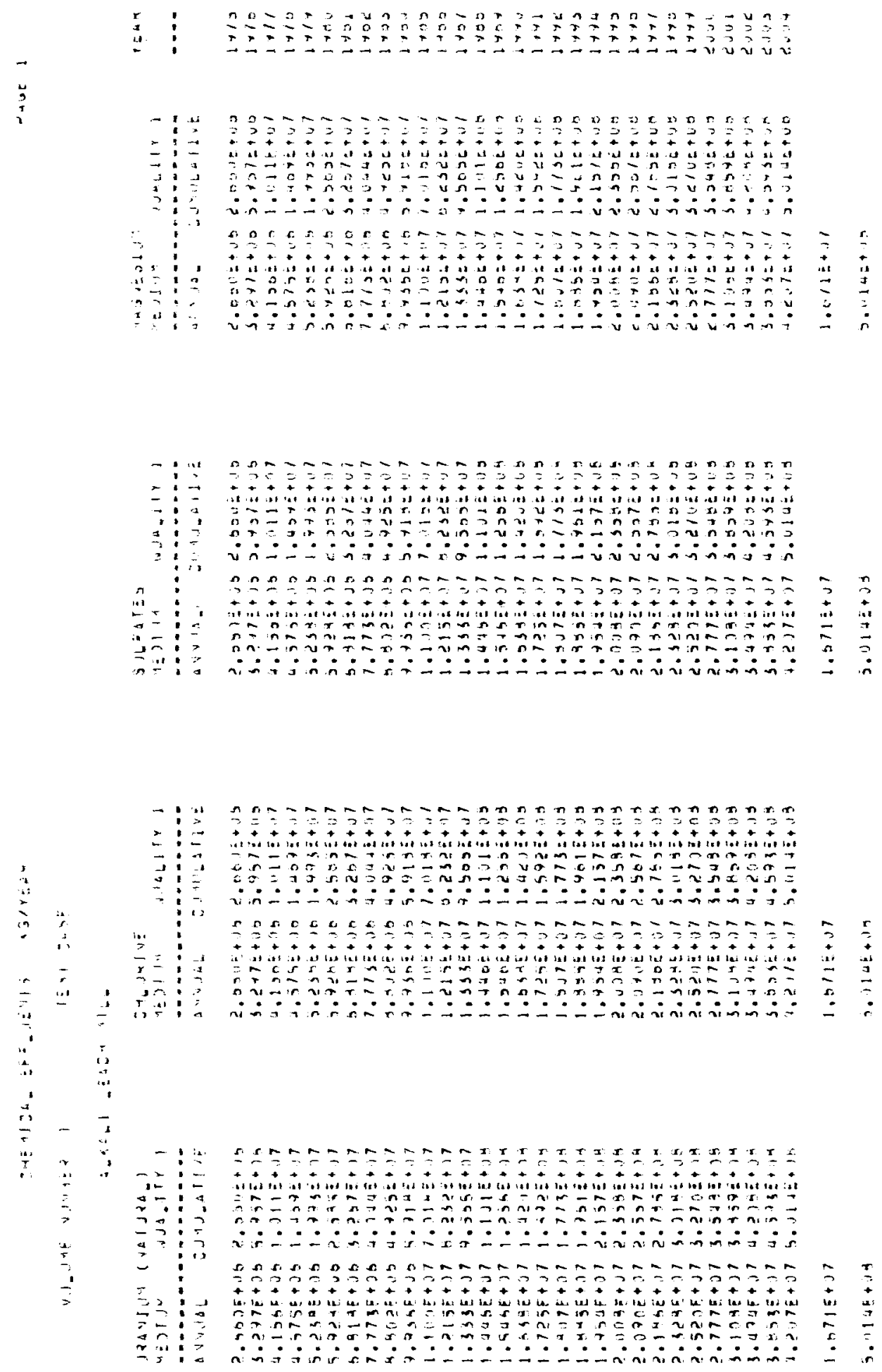

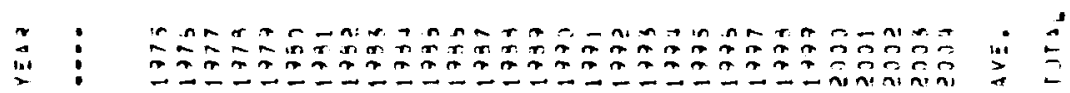



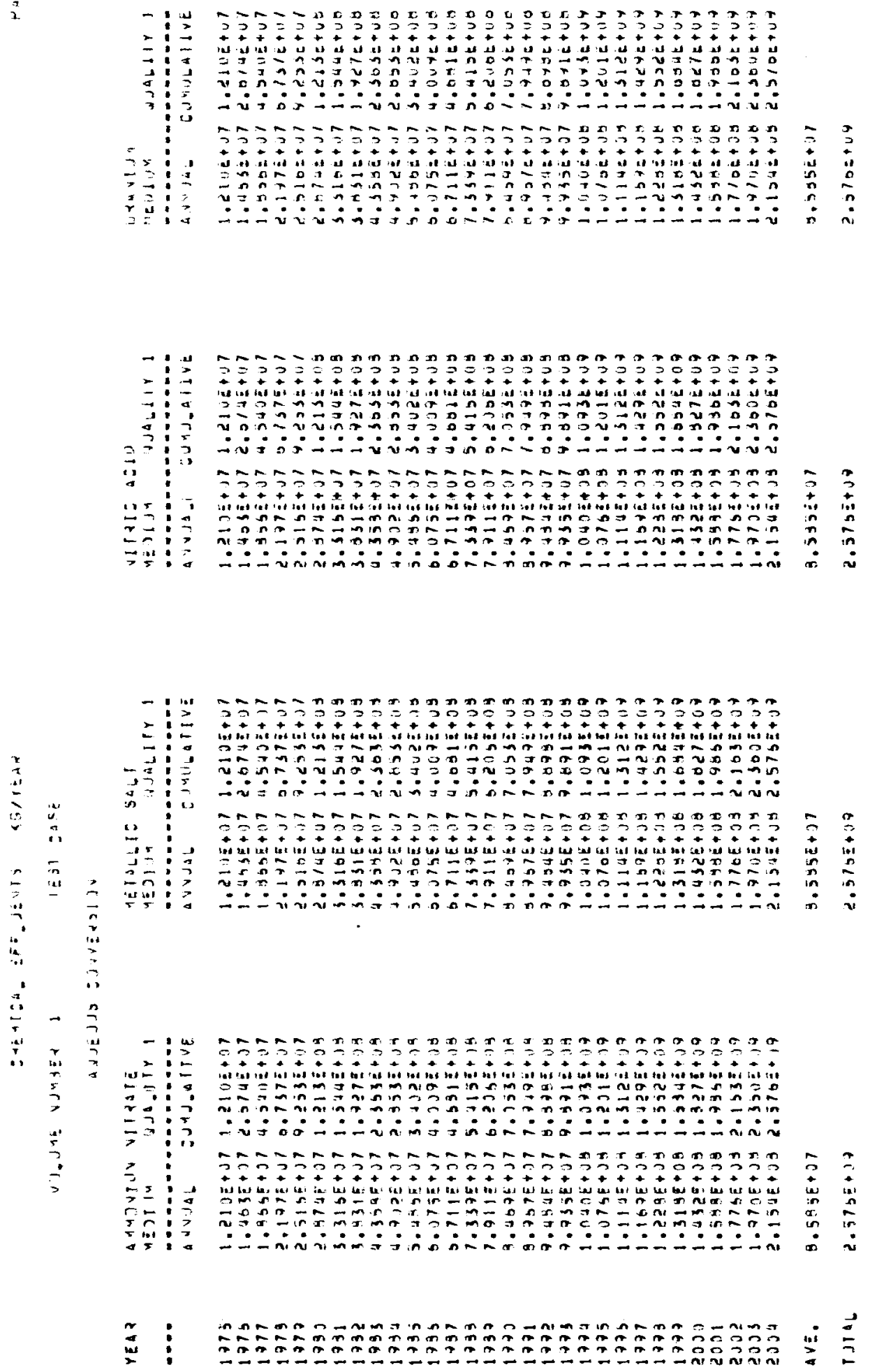


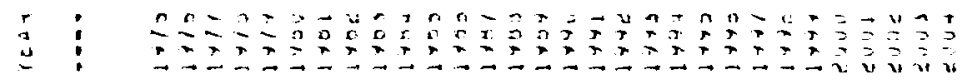
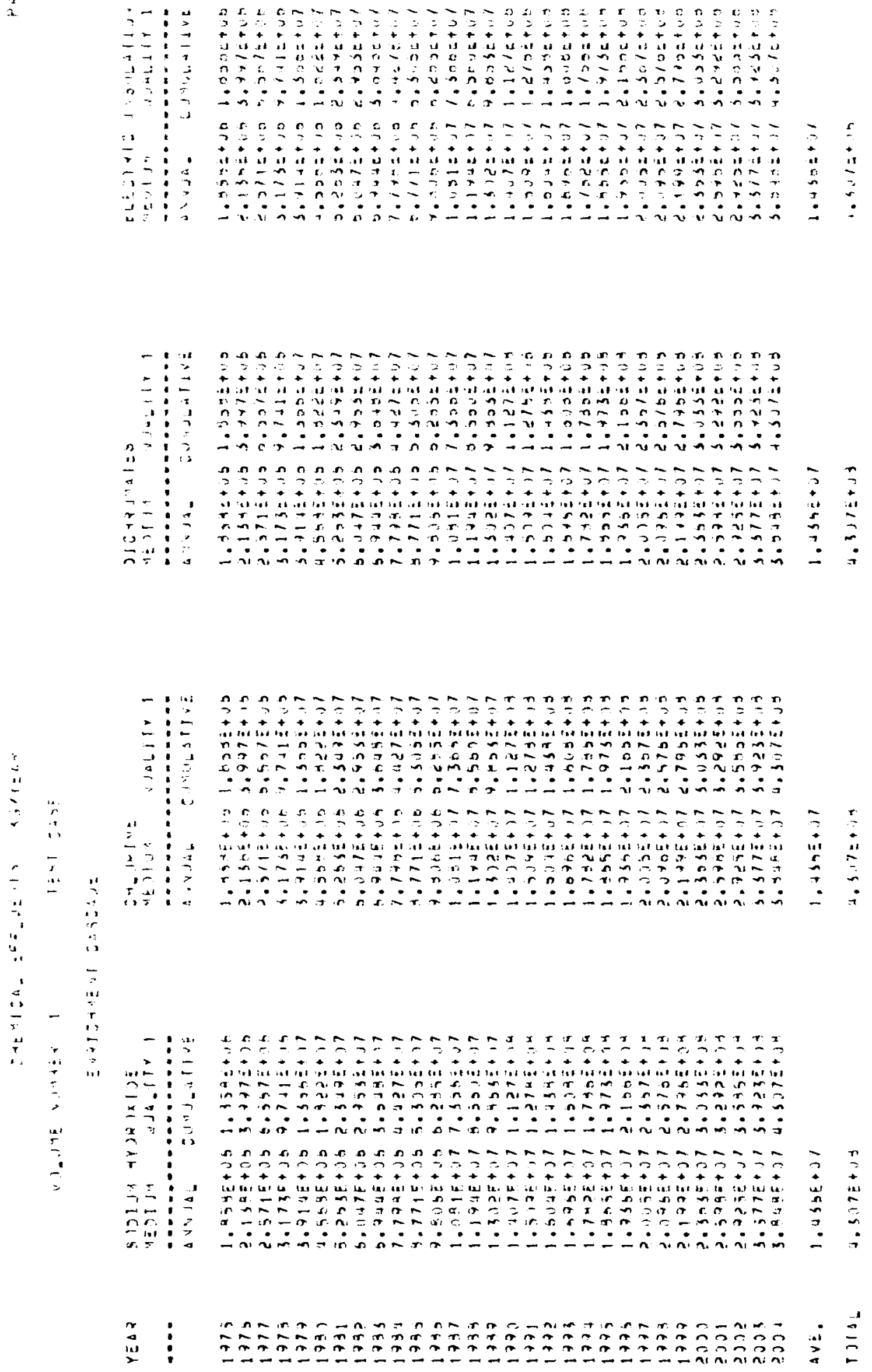


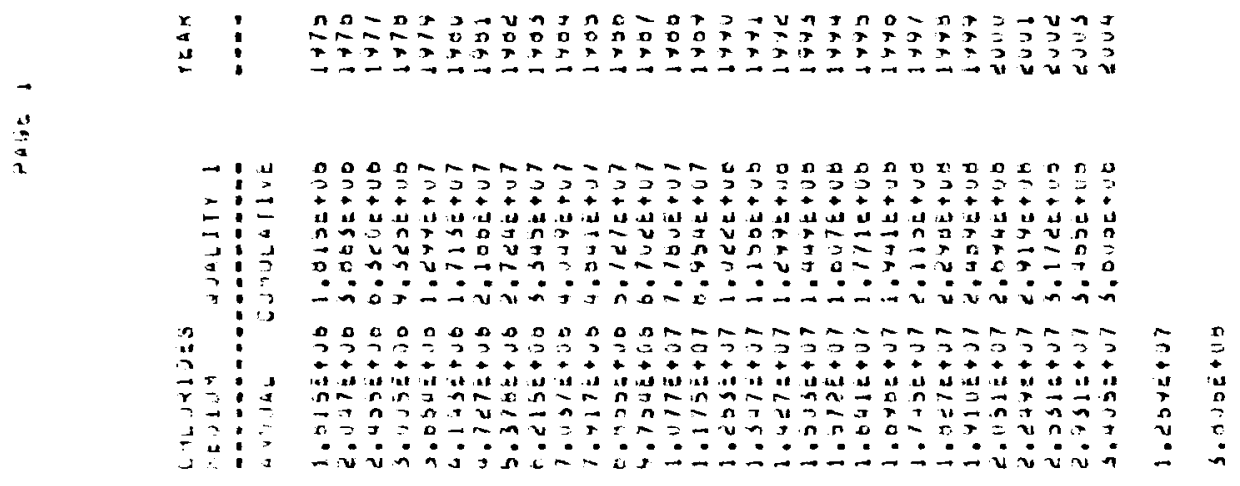

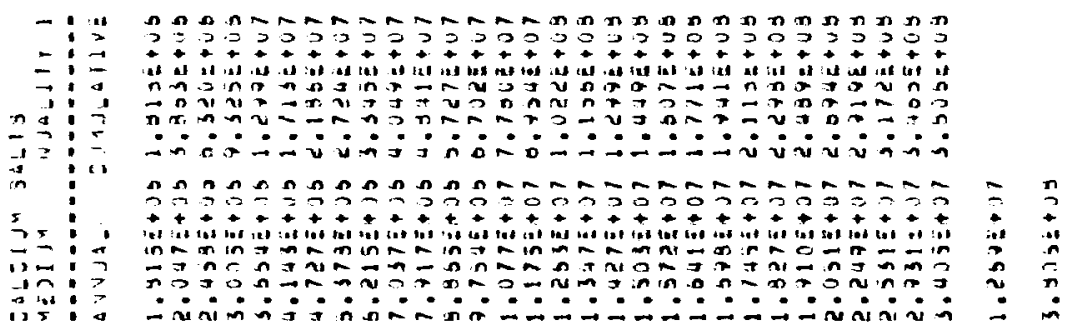

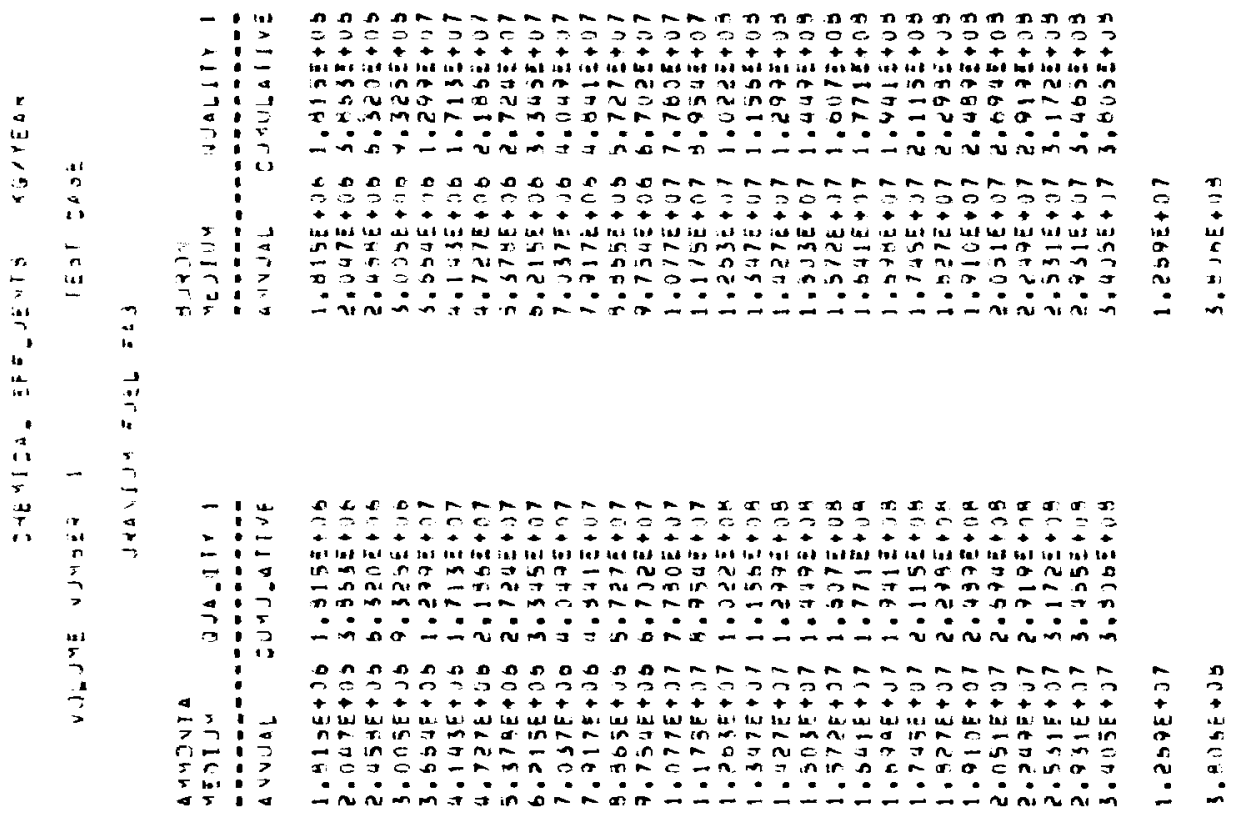

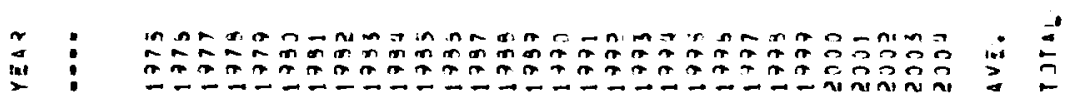




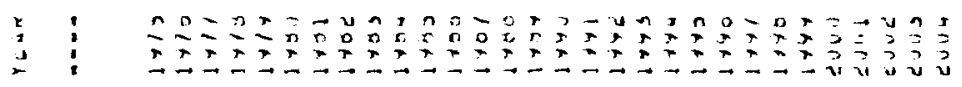
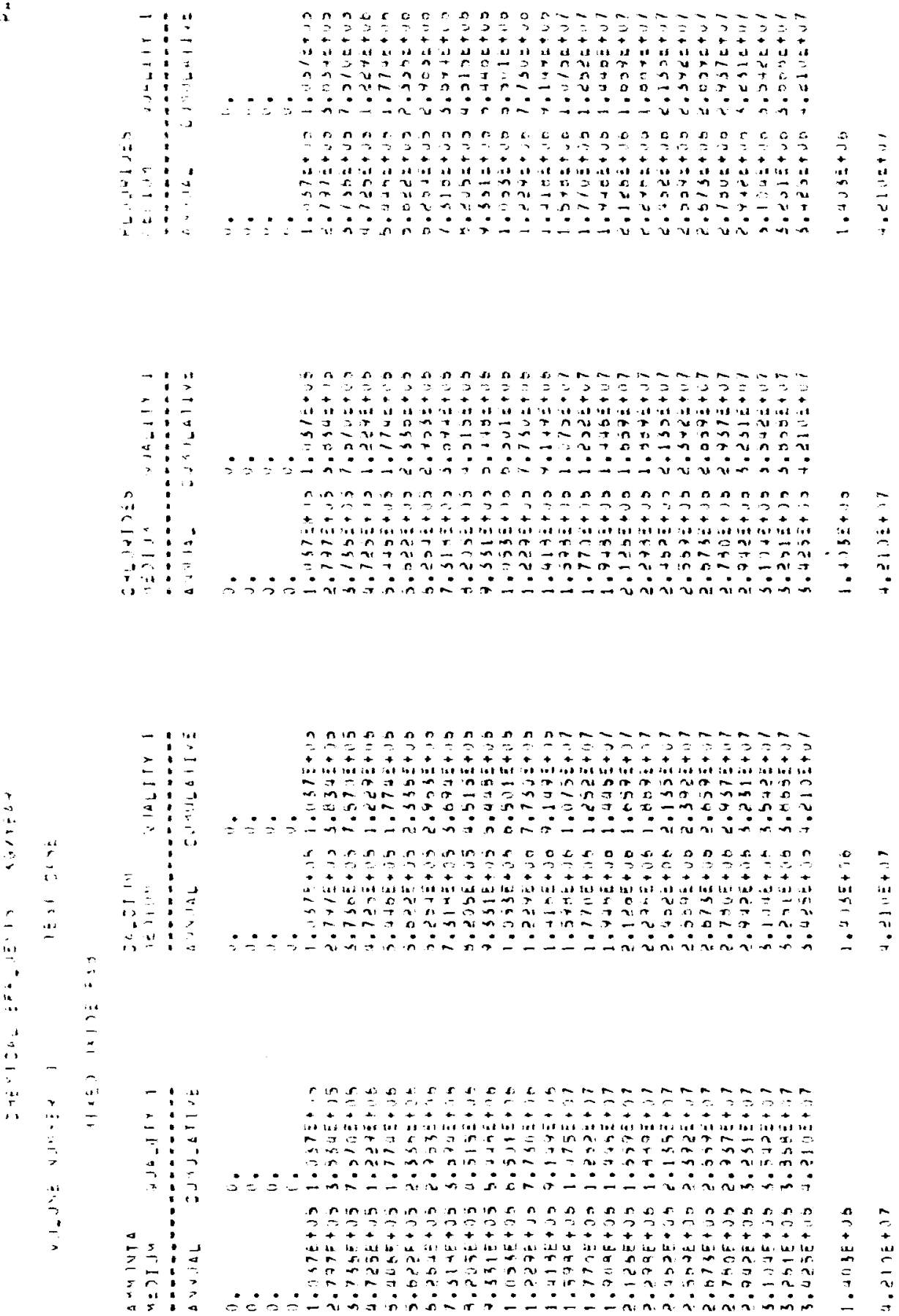

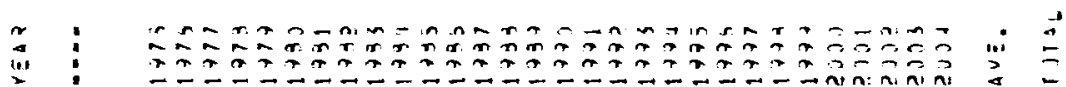



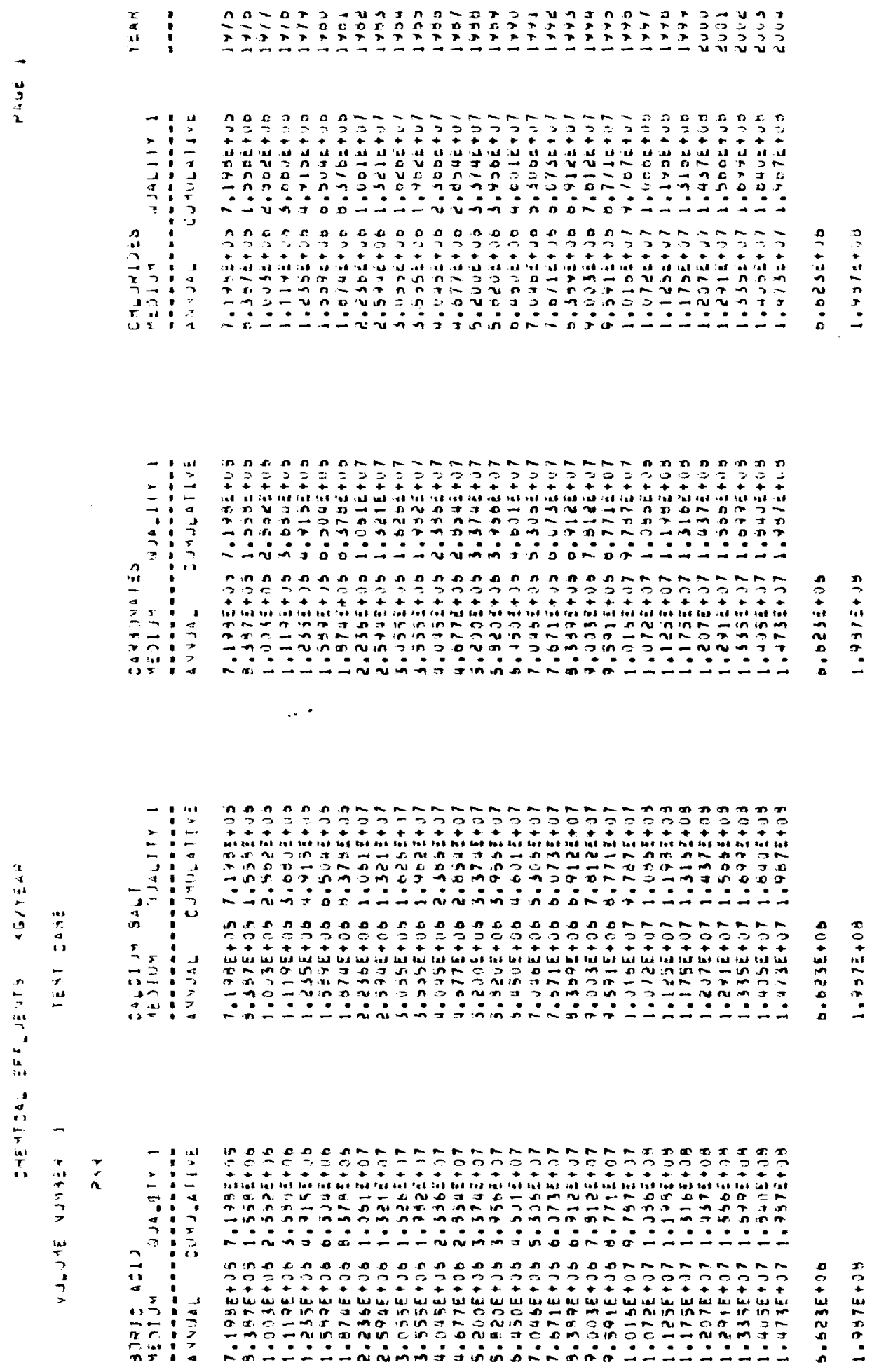

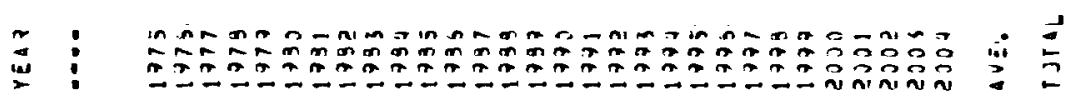




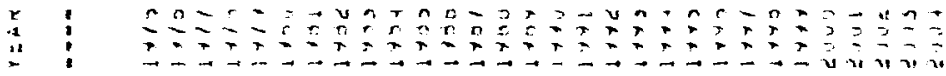

?

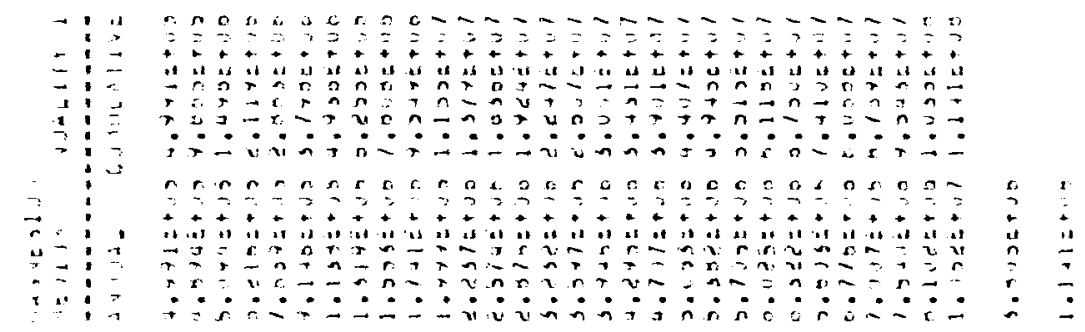

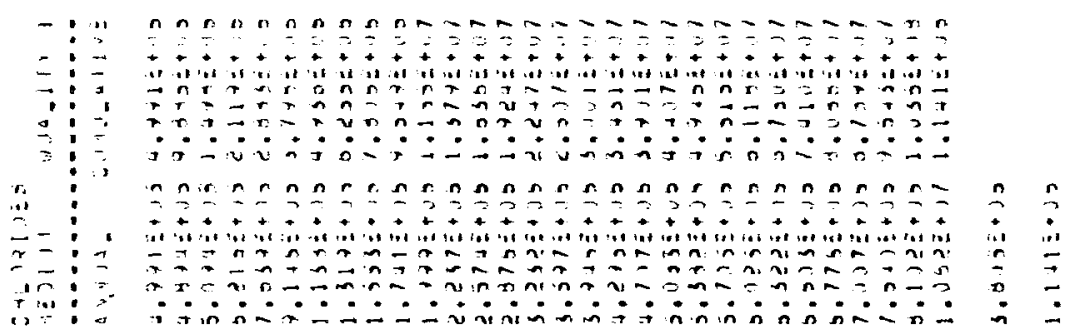

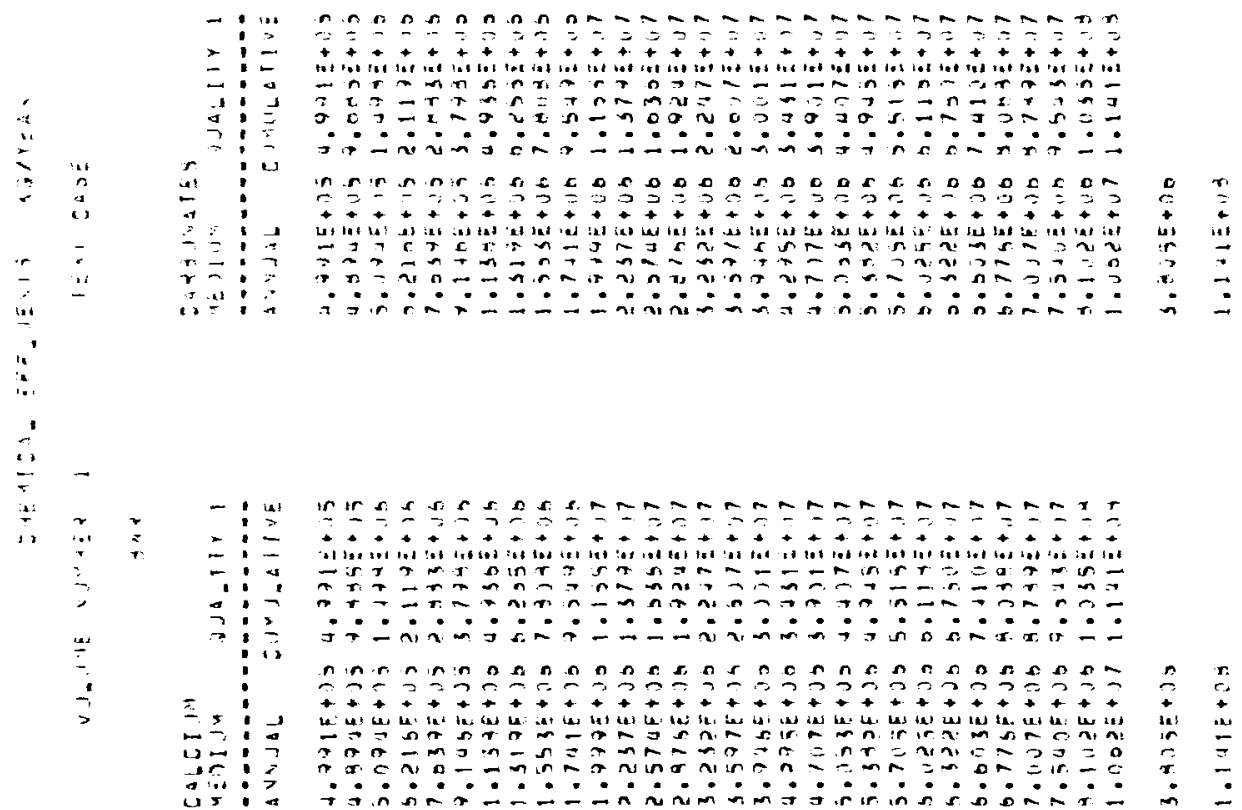

ำ 


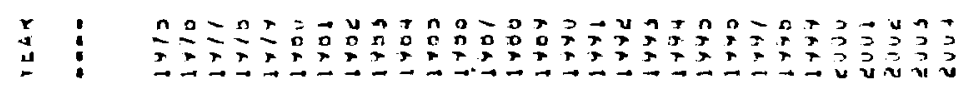
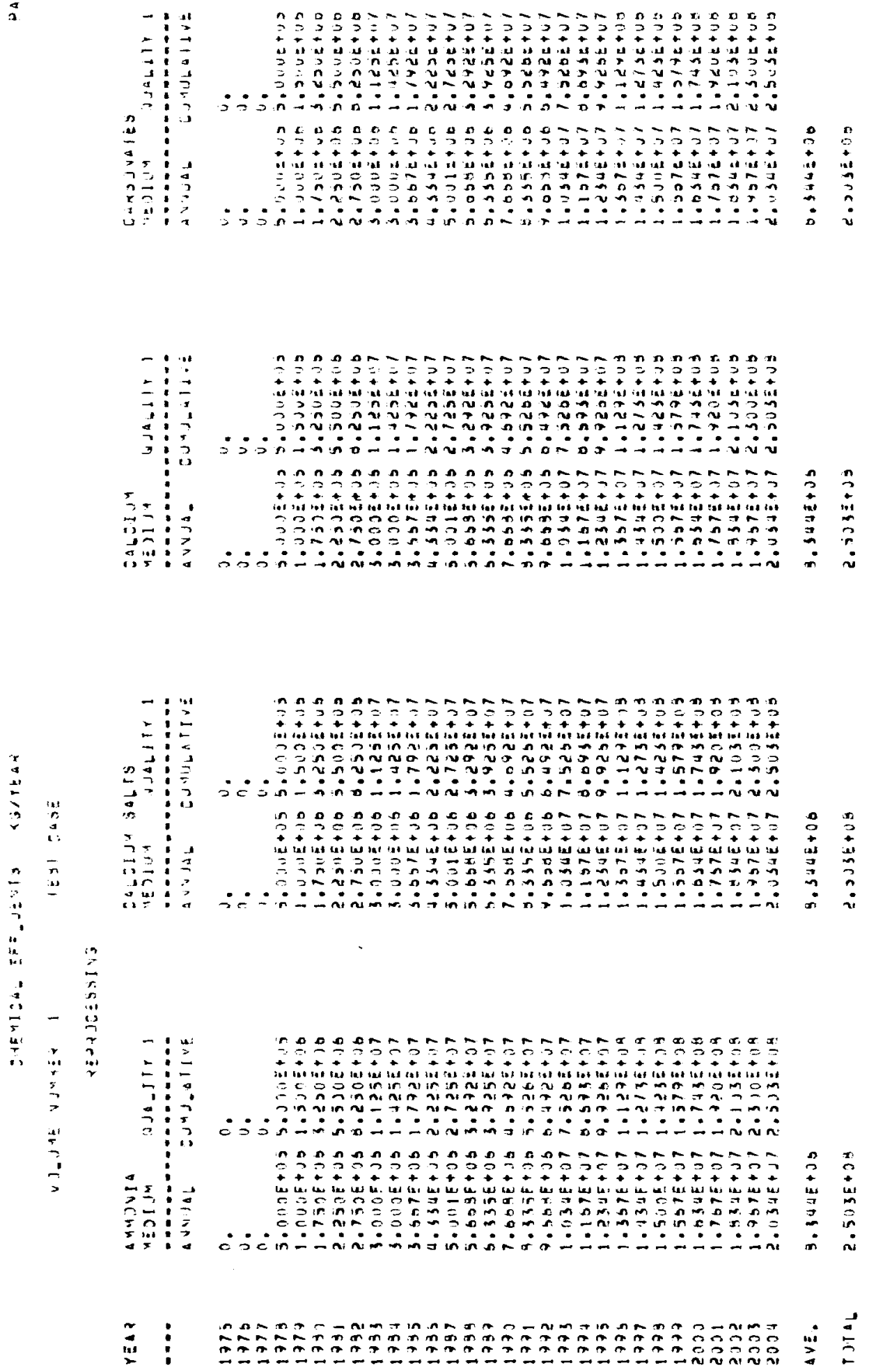



\section{APPENDIX C}

\section{DEFINITIONS OF VARIABLES}

The names and brief descriptions of the variables used in ENFORM-I are catalogued here. Just the briefest description is included in this appendix which is the group of comment cards used in the main subroutine BOSS. 



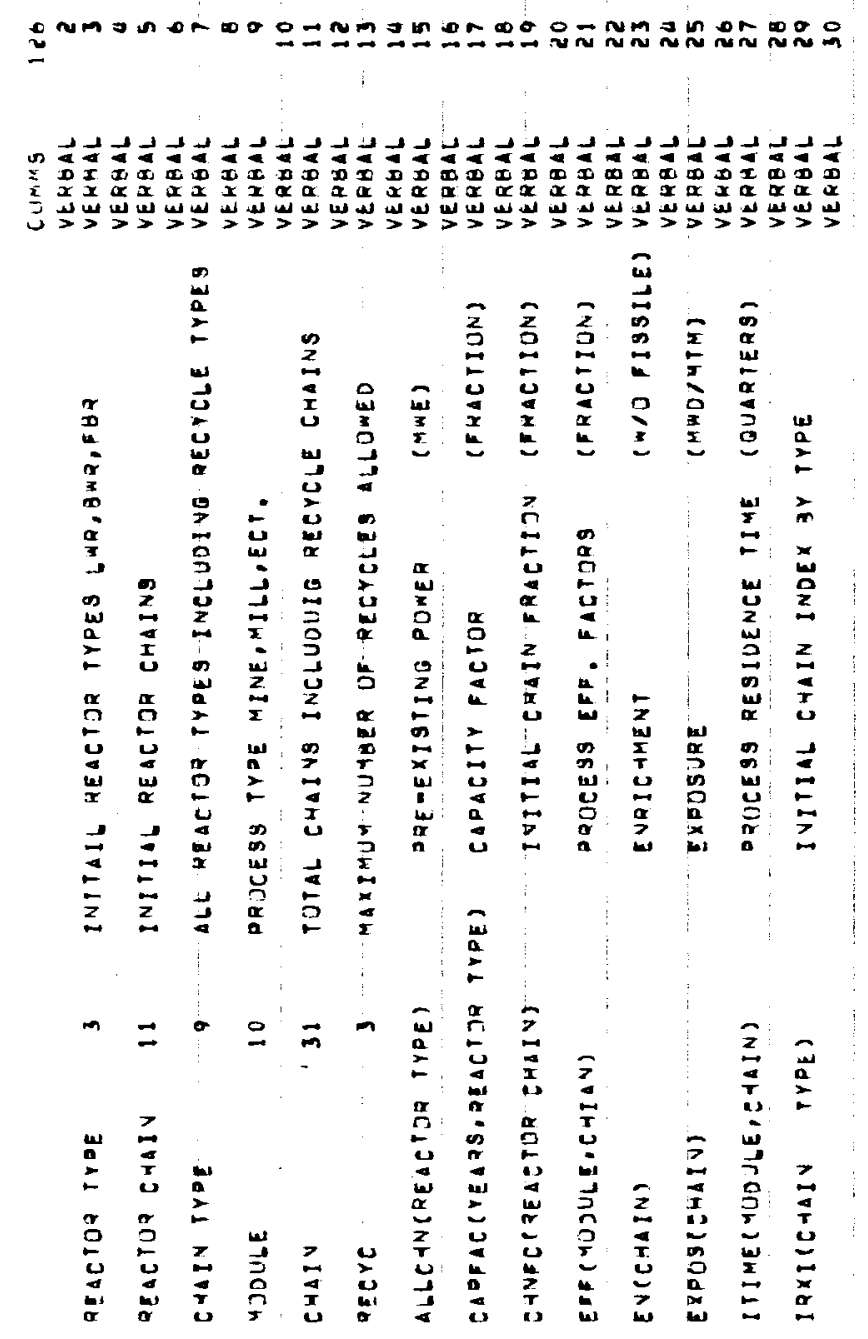

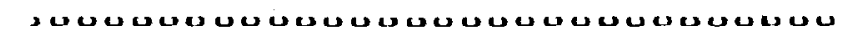

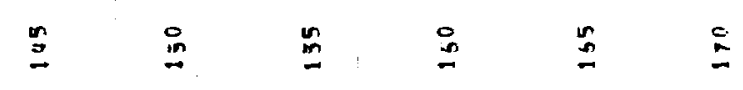




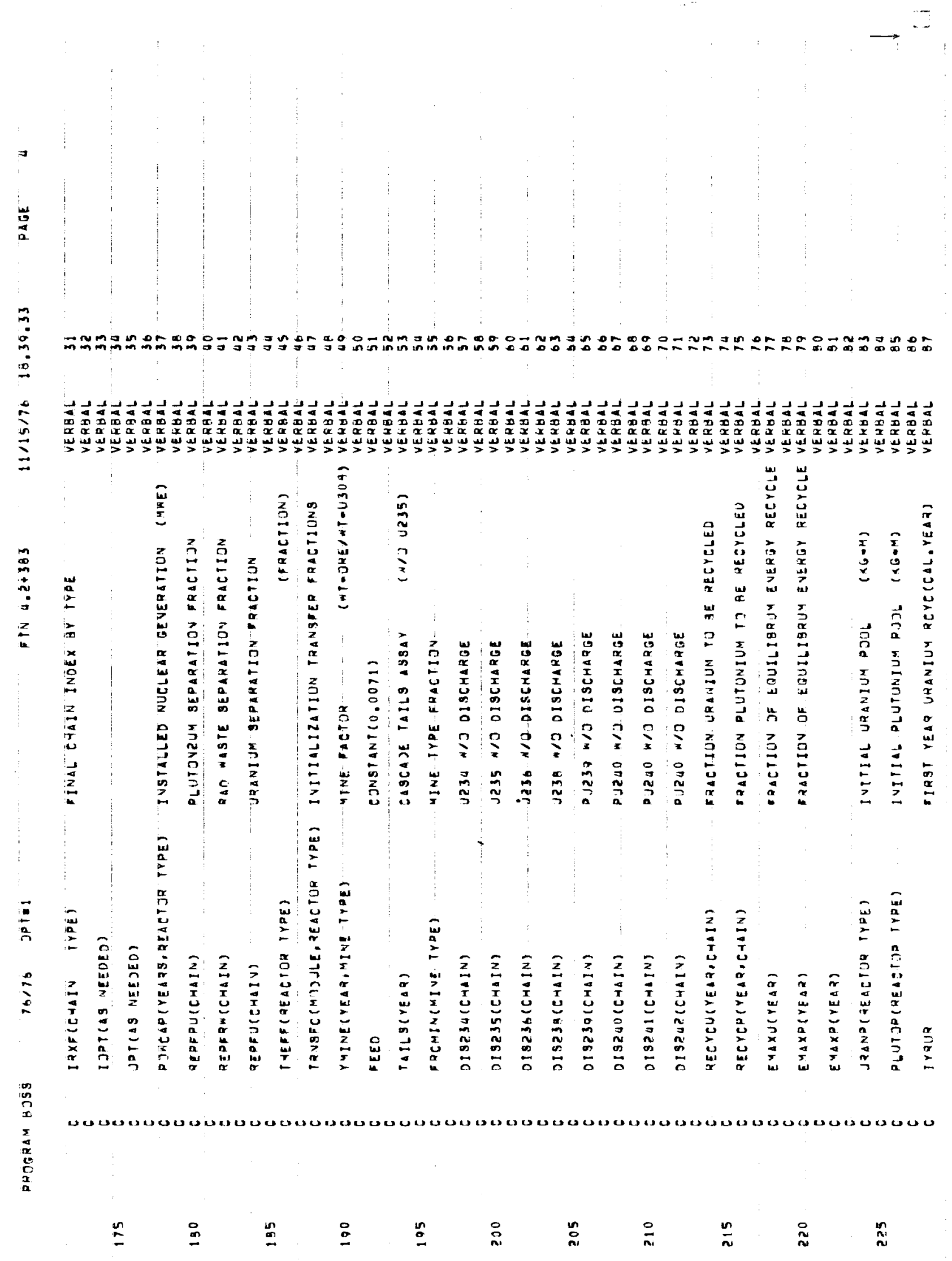



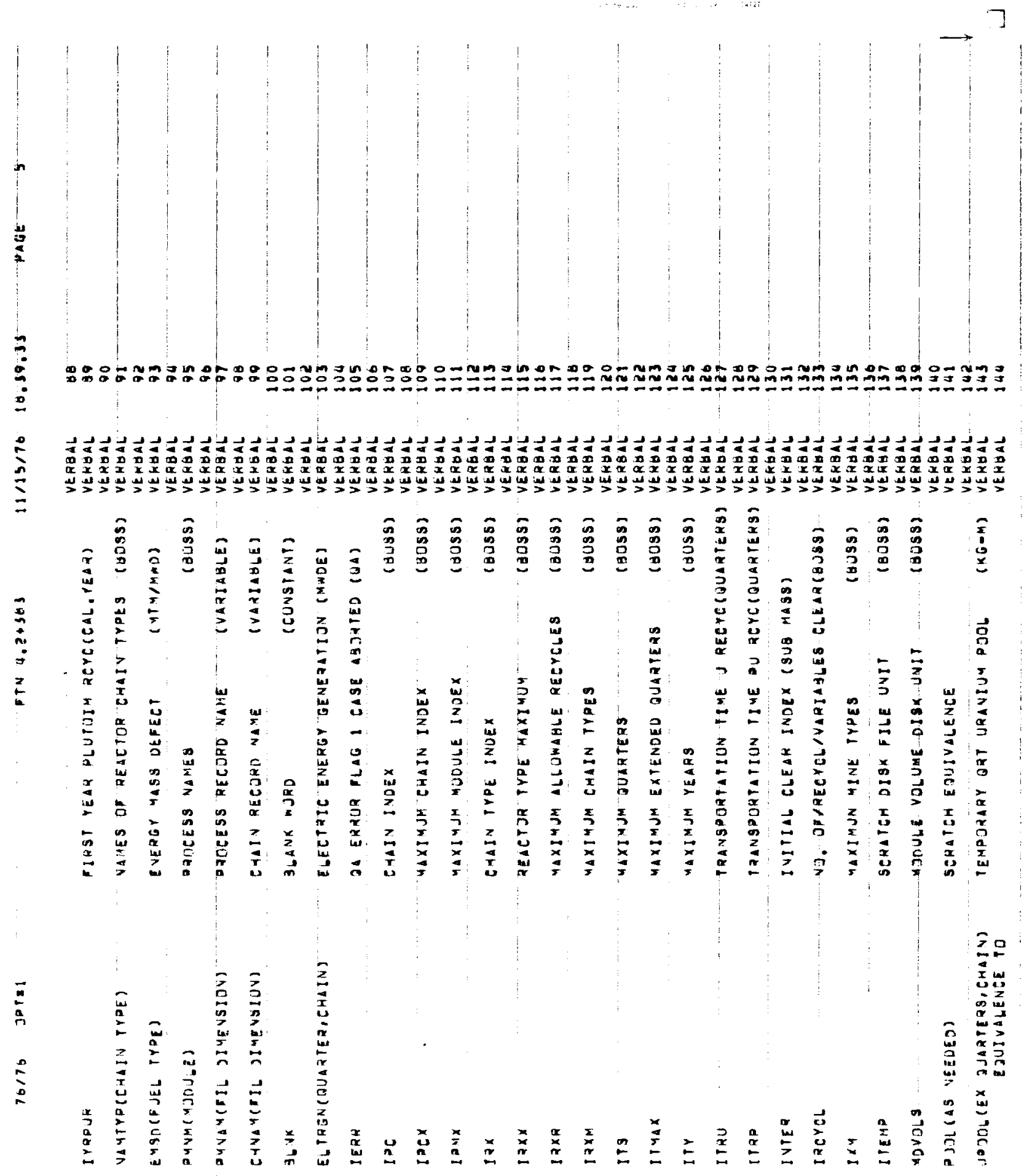

$n$
$n$
$n$
$n$
$\Sigma$
$\Sigma$
$\alpha$
$\alpha$
0
$\alpha$
$\alpha$
0

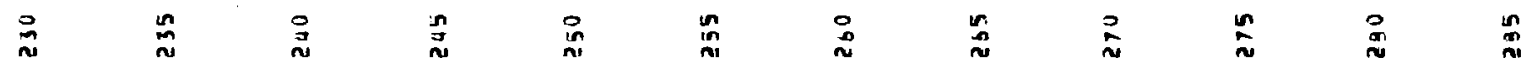




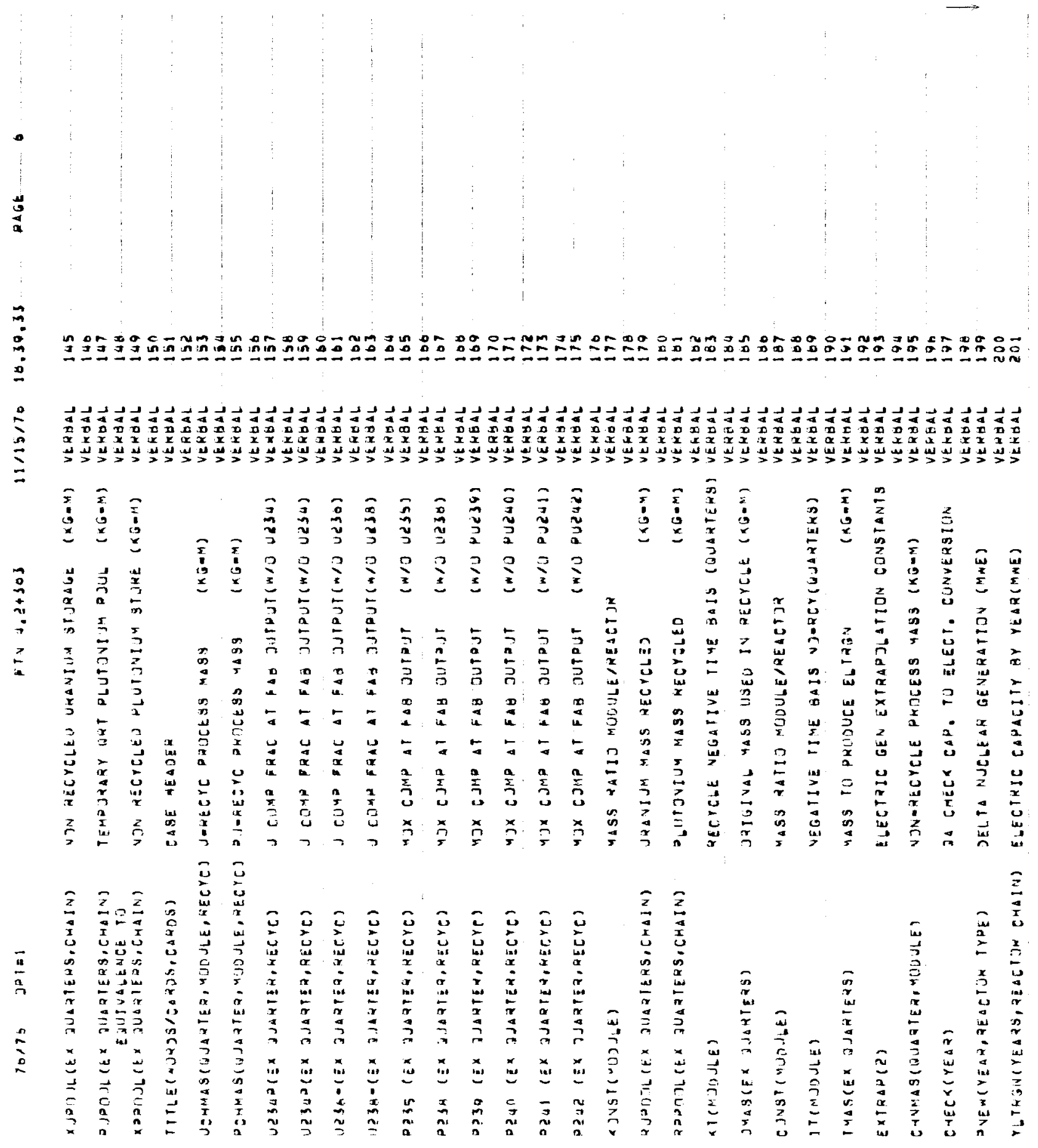

$n$
$n$
0
$x$
$a$
$a$
$x$
5
$x$
$x$
$a$

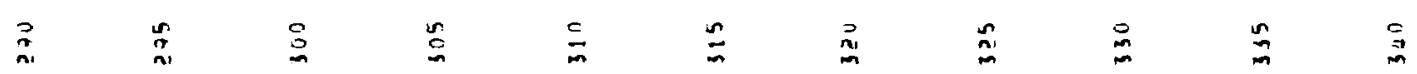




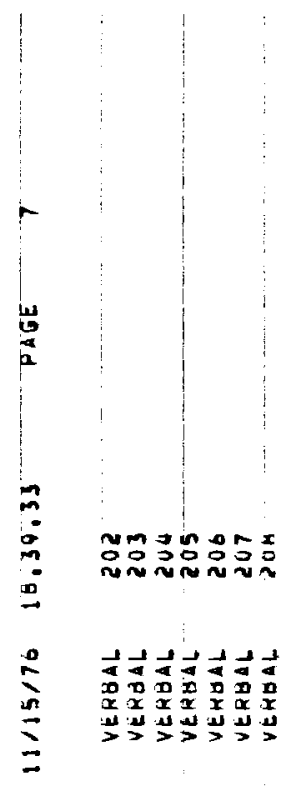

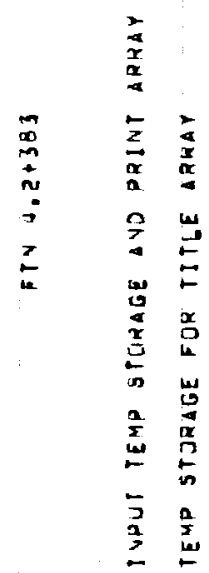

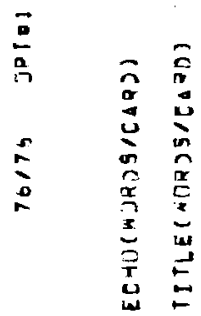

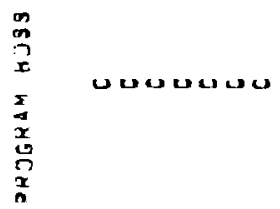

$\stackrel{\text { in }}{\exists}$ 


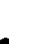




\section{DISTRIBUTION}

No. of

Copies

OFFSITE

1 ERDA Chicago Patent Group

U.S. Energy Research and Development Administration

Argonne, IL 60439

A. A. Churm

27 ERDA Technical Information Center

H. Glauberman

Division of Environmental

Control Technology

Germantown, MD 20767

A. F. Kluk

Division of Environmental

Control Technology

Germantown, MD- 20767

J. L. Liverman

Office for the Assistant

Administrator of Environment

and Safety

Germantown, MD 20767

W. E. Mott

Division of Environmental

Control Technology

Germantown, MD 20767
No. of

Copies

ONSITE

1 ERDA Richland Operations Office H. Ransom

32 Battelle-Northwest

D. L. Brenchley

N. E. Carter

B. M. Cole

R. M. Fleischman

C. M. Heeb (10)

U. P. Jenquin

T. J. Kabele (5)

M. A. Lewallen

R. C. Liikala

E. T. Merrill

D. F. Newman

T. B. Powers

W. L. Purcell

K. J. Schneider

J. R. Young

Technical Information Files (3)

Technical Publications (1) 


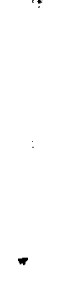

